\title{
The Guatemalan Construction Industry: Approach of Knowledge Regarding Work Risks Prevention
}

\author{
Francisco Arturo Hernández-Arriaza ${ }^{1}$, José Pérez-Alonso ${ }^{2, *}$, Marta Gómez-Galán ${ }^{2}$ and \\ Ferdinando Salata ${ }^{3}$ (D) \\ 1 Escuela Mecánica Industrial, Faculty of Engineering, University of San Carlos, Edificio T-1, \\ Ciudad Universitaria Zona 12, Guatemala C.A. 01012, Guatemala; faha04@gmail.com \\ 2 Department of Engineering, University of Almería, Agrifood Campus of International Excellence (CeiA3), \\ 04120 Almería, Spain; mgg492@ual.es \\ 3 Department of Astronautics, Electrical and Energetics Engineering, University of Rome "Sapienza", \\ 00184 Rome, Italy; ferdinando.salata@uniroma1.it \\ * Correspondence: jpalonso@ual.es; Tel.: +34-95-001-5502; Fax: +34-95-001-5491
}

Received: 11 September 2018; Accepted: 12 October 2018; Published: 15 October 2018

\begin{abstract}
In the present work, the results are presented for the characterization of work risk prevention in the Guatemalan construction industry. This characterization has been carried out using a simple random sampling technique, employing a questionnaire that was structured into 3 groups of variables: 1 . General company data; 2 . Prevention and management activities regarding health and safety in the company and on the worksite; and 3. Health and safety in the contractor companies. Following the sampling phase, the data were introduced in a database format, and a preliminary analysis was performed on the studied variables, followed by a descriptive analysis and a multiple correspondence analysis. The main findings of the study emphasize that companies in the Guatemalan construction sector are characterized as dedicating most of their activity $(52.0 \%)$ indistinctly between civil engineering work, building construction and other specialized construction, mainly working as contractors (47.5\%). These are "medium-sized" companies, employing an average of 81.1 on-site workers, having an average of 6.8 on-site work crews, and grossing an average turnover of 1.29 million euros annually. Likewise, it found that the larger construction companies adopt better prevention and management measures for worksite health and safety the larger companies are correlated with a high awareness of experiencing worksite accidents, while medium-sized companies have medium-level awareness. Companies with fewer workers manage workplace risk prevention worse, with low accident risk awareness. This correlation between these indicative variables of company size and workplace risk management and prevention is clearly reflected in the four company "clusters" that have been identified as having homogenous characteristics using the multiple correspondence analysis technique. Companies in the Guatemalan construction sector should make a greater effort to improve manager and worker training regarding workplace risk prevention to increase the effectiveness of company prevention management.
\end{abstract}

Keywords: Guatemala; health and safety in the workplace; prevention; contractor; construction companies; multiple correspondence analysis

\section{Introduction}

The construction sector registers very high labor accident rates in relation to the indices of other activity sectors [1-7] and as a consequence, there are high costs associated with work accidents that may depend on the culture, the risk level, the number of operators and the participation of subcontractors on 
each project [8-11]. Even López-Valcarcel [12] has written that more than half of all workplace injuries and deaths worldwide are attributed to, or are the responsibility of, the construction industry [13].

The culture of many workers helps to explain the high incidence rates in the construction industry. Factors such as machismo, substance abuse, language barriers and the low level of education are some of the most relevant aspects related to the worker's culture [14]. According to Hinze and Wiegand [15], the attitude of construction workers increases risk tolerance and, therefore, the frequency and severity of accidents. Two main reasons have been used to explain this high accident rate in the construction industry [14]: (1) the intrinsic risk due to the nature of the activities and the particular characteristics of the construction projects and organizations and (2) the financial and economic issues related to the implementation of additional security measures in a competitive growing market.

Therefore, the internal information on the cost of accidents generated during the work's execution, as well as the phases in which they are produced, could help in making decisions regarding safety [8]. In this sense, Arévalo indicates that knowing the economic repercussion of accidents, from the design phase and its prevention measures, would make it possible to delimit a more efficient security management system in the company from its origin, as well as deepen the prevention and study of accidents, and provide enough personal protection equipment (PPE) [16]. Complying with PPE use and availability, which may depend on the size of the organization and the type of training for its use [17], as well as other security measures, is required to reduce injuries and fatal accidents among construction workers [18-20] or among visitors to the construction site [21,22].

Safety is a process that considers the use of all types of tools and techniques to systematically guarantee worker's well-being [23-25]. Thus, the main factors that affect safety in construction companies are poor safety awareness by top management, poor training, poor safety awareness by safety coordinators and drafters of projects, reluctance to provide safety resources and reckless operations [26].

To prevent accidents, exhaustive maintenance is necessary along with periodic safety inspections, continuous safety training and the development of an accident investigation plan [27]. Therefore, there are a wide variety of works that investigate the causes of construction accidents and affect the safety of workers, such as the company size, its safety policy, the attitude of workers, preventative coordination at the project and execution phase of the planned work [15,28,29], and safety management in the company $[26,28,30]$. Thus, for example, the causes of accidents that occurred in construction and their relationship with the construction phase in which they occur are analyzed [29].

Prevention ought to be considered from the moment a professional initiates a workplan or starts a job, involving designers and contractors [31-33], giving the importance of the safety and health coordinator's role, for their participation in the distinct phases of the project [5]. Therefore, it is recommended that the safety and health management in construction projects present an integrated approach, so that it involves all stages of the project's life cycle: design, execution, and operation. In this sense, a lot of researches have been carried out on the risks prevention through design (Construction Hazard Prevention through Design (CHPtD)), that is, integrating worker safety prevention measures into the design phase of the project by the designers of the construction sector [34-36]. Another step in the prevention of risks through design is the new Building Information Modeling (BIM) system that aims not only to improve safety but also productivity [37-39].

As we have seen, safety and health at work in the construction industry has been and continues to be a subject of intense research and practical development. Worldwide, there has been a substantial improvement in occupational safety and health in the construction industry, generally motivated by the publication and continuous implementation of the most relevant standards in the field ILO-OSH 2001, OHSAS 18001, and ISO 45001 [40-42], and increasingly strict regulations [14].

However, developing countries do not adapt quickly enough to the implementation of this regulatory body, which is why they present more problems of accidents. Thus, it was not until 1957 that Guatemala established the General Law for Health and Safety in the workplace [43], and it was not until 7 October 1991 that agreement 167-1988 concerning health and safety in the building sector was 
approved [44]. In Guatemala, according to the Guatemalan Institute of Social Security hospital register of accidents out of the manufacturing-construction-service industries in 2016, 28.15\% corresponded to construction (24.75\% in 2017) [45]. As in any developing nation, the risk of having one's health impacted is 10 to 20 times greater than in industrialized nations [13,46].

For all of the aforementioned reasons, and given that no scientific documentation exists regarding workplace risk prevention in the Guatemalan construction industry, the objective of this study is to characterize workplace risk prevention in Guatemalan construction companies in a way that correlates company size with prevention activity parameters and workplace risk management, as well as other corresponding structural and organizational parameters.

\section{Materials and Methods}

\subsection{Research Design}

To characterize workplace risk prevention in Guatemalan construction companies (see Figure 1), the quantitative and qualitative variables expounded in Tables A1-A6 (see Appendix A) have been adopted as study variables; these are grouped into 3 groups of homogenous variables. Only those in the first group, namely those describing company generalities, are there 5 quantitative variables (Annual company turnover (C), the number of workers in the office (D), the number of workers on site $(\mathrm{E})$, the number of work crews over the year $(\mathrm{F})$, and the number of years experience working on site $(G))$. All the other variables are qualitative. However, the quantitative variables are categorized to better study and correlate them. In Tables A1-A6, one can see all the variables and their nomenclature, and for the qualitative and quantitative variables categorized, their categories and nomenclature are shown.

To acquire the field data for the studied variables, a sampling was carried out of Guatemalan construction companies using a questionnaire designed for the task. Once the data were obtained, a preliminary analysis was carried out to identify absent and missing data, and then we checked that the data verified the conditions of independence, homoscedasticity, and normality of the variables. With the aim of better understanding the interrelationship between the variables, a bivariate correlation analysis was performed on the variables, calculating the Spearman correlation coefficients. Likewise, a descriptive analysis was performed on the studied variables-for the qualitative variables, the frequency for each category of each expressed variable was described in percentages, whereas for the quantitative variables, their average values were determined along with the standard deviation. Finally, multiple correspondence analysis was performed that allowed one to determine which variables, and which categories for each variable, corresponded with each other, to know if significant correspondences existed between categories of variables, and groups of companies with common characteristics.

\subsection{Questionnaire Development}

To collect the information, a specific questionnaire was designed, based on previous Spanish research works $[47,48]$, which were structured into three sections that grouped homogenous variables. These three groups of variables were:

1. General Company Data: containing 8 variables (Table A1, see Appendix A).

2. Prevention Activities and Health and Safety Management in the Company and on the worksite; containing 38 variables (Tables A2-A5, see Appendix A).

3. Health and Safety in the Contractor Companies: containing 11 variables (Table A6, see Appendix A). 


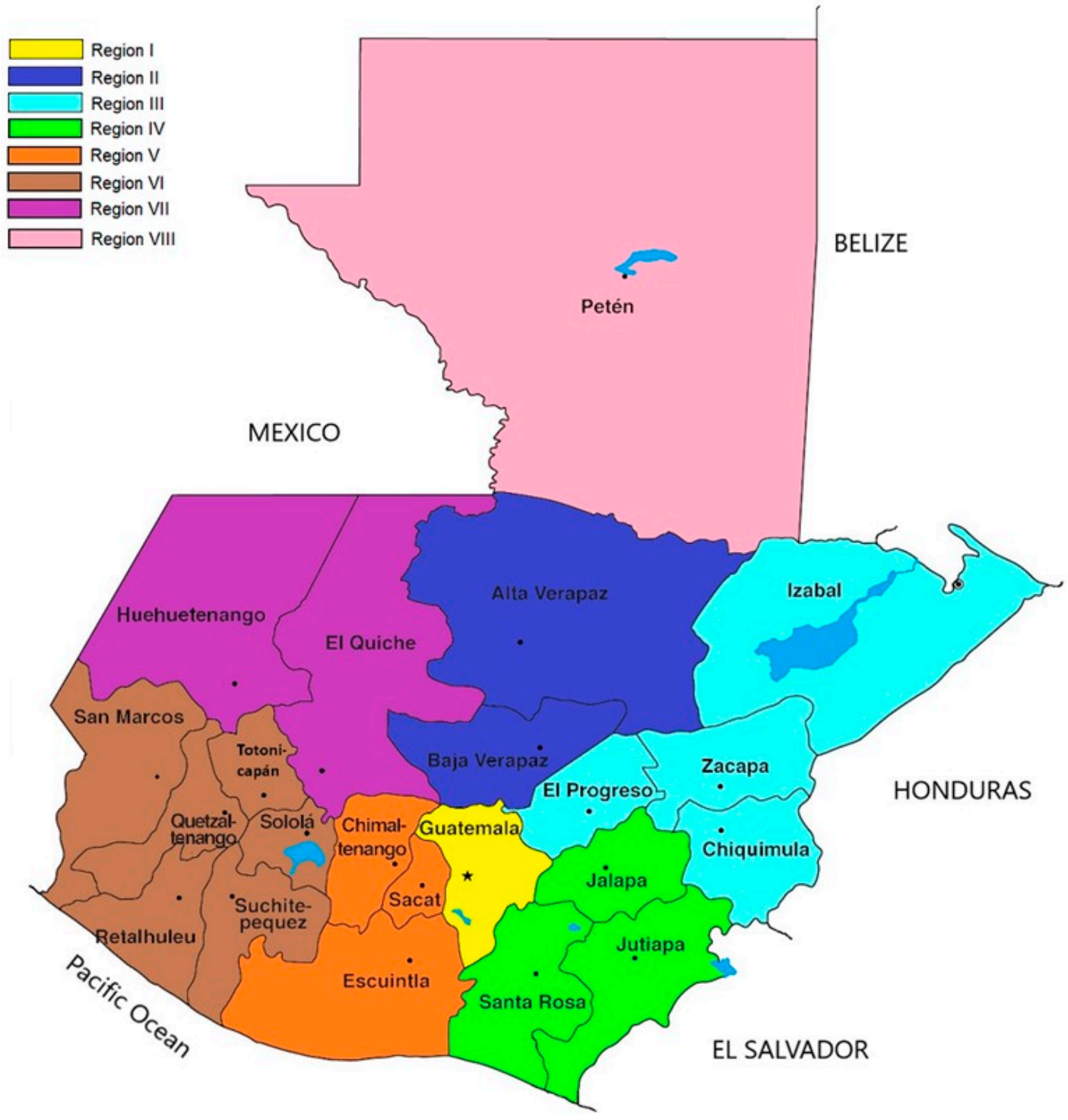

Figure 1. Map of the territorial division of Guatemalan departments.

\subsection{Sample}

A simple randomized system was used to perform the sampling, considering the population to be the totality of construction companies in Guatemala that, according to the country's National Statistics Institute was 7720 companies as of December 2015 [49]. However, to gather reference data on them, we turned to the Ministry of Communications, Infrastructure and Housing (Ministerio de Comunicaciones, Infraestructura y Vivienda (MICIVI)) which provided the database of existing prequalified companies (namely, the address, legal representative, telephone, e-mail, financial standing, and date of incorporation), which as of December 2015 totaled 1954. For the sample size extraction, with a confidence level of $95 \%(Z=1.96)$, an acceptable error limit of $7 \%$ and a standard deviation of $5 \%$ resulted in a sample size of 178 companies. This amount is equivalent to $9.11 \%$ of registered companies. To guarantee the present research, we initially sent 5 surveys that, on being received, generated a receipt validation with small modifications in the questioning. In total, 350 surveys were sent out to Guatemalan constructors via the Internet using the Google Forms application as well as by printed paper (17.91\%); this resulted in 86 being sent back to us digitally, of which 18 were removed because no more than $30 \%$ of the total survey was completed. Of the printed versions, a total of 34 were returned, of which 2 were discarded for the same reason (so as not to skew the results of the 
present research)—this left 100 effective samples with significant responses. The sampling period was from March 2016 to December 2017.

\section{Results}

\subsection{Response Rate and Consistency}

In accordance with the sampling plan indicated in Section 2.3, 350 surveys were sent out, of which 100 were valid; thus, the effective response rate was $28.57 \%$, less than the $38.0 \%$ obtained by Chen and Mohamed in a sampling study of building contractors in Hong Kong [50].

To study the consistency of the variables analyzed in the present study, a correlation analysis was performed on the variables using the Spearman rank correlation coefficient for each pair of variables, because, in accordance with Pérez-Alonso and collaborators [48], this coefficient shows the level of superposition of variable fields, such that if the value is greater (e.g., greater than 0.80 ), multicollinearity would exist between them, and thus indicate that identical fields are represented, and that some of the statistical analysis variables should be discarded. As a result, the variables presenting correlation coefficients greater than 0.80 were discarded from the multiple correspondence analysis (MCA), thus controlling the multicollinearity of the variables, leaving the correlation coefficients for the remaining variables between 0.15 and 0.728 .

\subsection{Descriptive Analysis}

In Tables A1-A6 (see Appendix A), the frequency for each of the qualitatively studied variable categories is shown along with those variables that were quantitatively categorized.

Regarding the quantitative variables, the companies in the sample presented an average annual turnover (C) of 1.29 million euros (s.d. 6.29), an average number of office workers (D) of 7.3 (s.d. 15.06), an average number of on-site workers (E) of 81.1 (s.d. 75.22), an average number of on-site work crews (F) of 6.8 (s.d. 5.55), and an average of 2.7 years of experience working on site (s.d. 0.55).

\section{3. $M C A$}

The results of the MCA performed for the representative variables (Table A7, see Appendix A) allow one to identify the correlation of the variable categories, as well as their own variables using a two-dimension model in which information regarding all analyzed variables is summarized.

\subsubsection{Reliability of the Multiple Correspondence Model}

The model obtained after the above analysis presented two significant dimensions, in which the first explained $39.4 \%$ of the variance with a Cronbach $\alpha$ coefficient of 0.972 and an eigenvalue of 22.079; while the second dimension explained $26.3 \%$ of the variance with a Cronbach $\alpha$ coefficient of 0.949 and an eigenvalue of 14.747-so that for the joint factorial model, the average variance explained is $32.9 \%$, the average Cronbach $\alpha$ coefficient is 0.963 and the average eigenvalue is 18.413 , signifying that there is good model reliability.

\subsubsection{Discrimination Measures}

In Table A7 (see Appendix A), the discrimination measures are shown for each variable regarding each of the two dimensions and the average. As can be appreciated, the lead variable in the ranking of explicative variables is AAA (0.628), since it presents the largest discrimination, followed in order of descending explanation by the variables $\mathrm{Z}(0.528), \mathrm{Y}(0.527)$ and $\mathrm{V}(0.523)$. The least explicative variable is $\mathrm{OO}(0.024)$, followed by EEE (0.030), $\mathrm{S}(0.117), \mathrm{Q}(0.118)$ and $\mathrm{A}(0.149)$. In terms of the discrimination in both dimensions, the first dimension presents very large discriminations with the variables AAA (0.805), KK (0.728), II (0.721), V (0.717), ZZ (0.695), Z (0.673), U (0.665), X (0.658), LL (0.623), M (0.621), $\mathrm{Y}(0.620)$ and $\mathrm{L}(0.610)$, while the second dimension presents large discriminations but less than those of dimension 1 , with the variables E (0.639), F (0.596), TT (0.579) and C (0.487). 
Each measure of discrimination coincides with the coordinate variance for each dimension of the modalities for each variable; such that the variables whose modalities have different coordinates for a dimension present elevated discrimination measures for that dimension. Likewise, discrimination measures similar to a variable in the two dimensions reflect difficulties in assigning them to a given dimension. The ideal is for a variable to have a high value in only one dimension and be low in the other, as occurs with the variables II, L, KK, LL and U, which are more correlated with dimension 1; therefore, the dimension better discriminates the categories of these variables; while the variables E, TT and F are more correlated with dimension 2-consequently, this dimension better discriminates the categories of these variables.

\subsubsection{Quantifications}

The MCA carried out allows one to identify the categories for each variable that discriminate the objects (companies) more; and thus, the quantifications of the variables are obtained and represented on a factorial plane, in which the axes are the two model dimensions (Figure 2). The quantification of the categories are the average scores for the objects of the same category; and through the representation of the factorial plane (Figure 2), we can observe the correlations and correspondences of the variable categories.

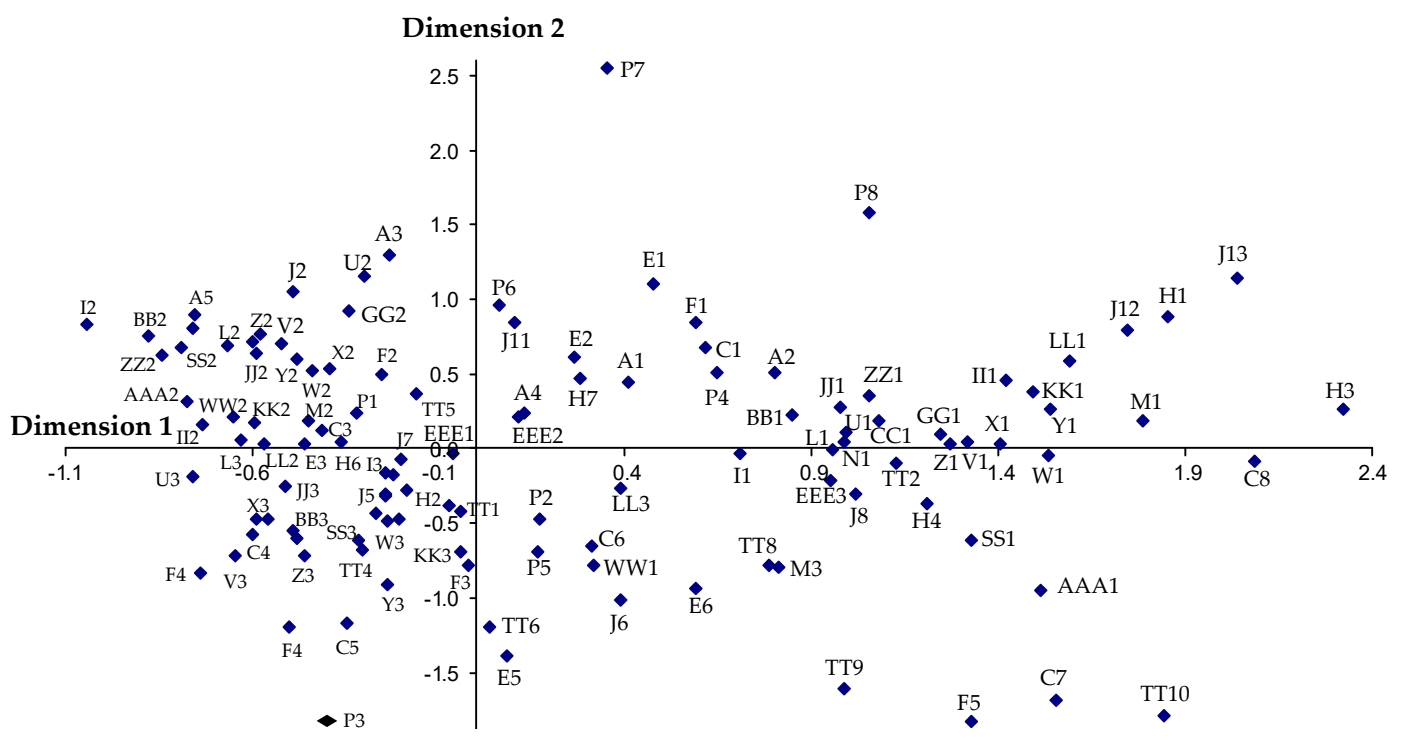

Figure 2. Factorial plane of the quantifications of the variable categories.

\subsubsection{Contribution of the Dimension to the Inertia of the Point for Each Variable}

In addition to the quantifications, to discover which category for each variable best contributes to each dimension, the correspondence analysis calculates the contributions of the dimension to the inertia of the point for each of the variables, which are shown below for five general company variables and the most significant of the other variables, expressed in percentages.

For variable $A$, the category that best explains the positive value of dimensions 1 and 2 is to present a building construction activity exclusively (A2) $(8.5 \%$ and $3.4 \%$, respectively) and for negative values to work simultaneously in civil engineering, building construction and specialized constructions (A7) (6.3\% and 9.7\%, respectively), since these present the largest dimension contributions to the inertia of the point for the variable.

For variable $C$, the category that best expresses the positive values of dimension 1 is that the company turns over between $2-10$ million euros (C7) $(10 \%)$, and for negative values that it turns over between $0.1-0.3$ million euros $(\mathrm{C} 2)(8.1 \%)$; while for positive values of dimension 2 , that it also turns over between 0.1-0.3 million euros (C2) (11.7\%) and for negative values, that it turns over between $0.7-1$ million euros (C5) (14.1\%). Regarding variable E, the category that best accounts for the 
positive value of dimension 1 are companies of between 11 and 50 site workers (E2) (3.8\%), and for negative values, companies of between 101 and 150 site workers (E4) (7.9\%); while for positive values of dimension 2, they are companies with between 11 and 50 site workers (E2) (20.4\%) and for negative values, companies with between 151 and 200 site workers (E5) (23.3\%).

For the $\mathrm{F}$ variable, the category that best accounts for positive values in dimension 1 is that the number of work crews is less than 4 (F1) $(8.5 \%)$, and for negative values, that the number of work crews is between 4 and 6 (F2) (2.0\%); while for positive values of dimension 2, that the number of work crews is less than 4 (F1) $(17.3 \%)$, and for negative values, that the number of work crews is between 7 and 10 (F3) (16.5\%). For the $\mathrm{H}$ variable, the category that best explains the positive value of dimension 1 is that the company works on the job as the developer and as the contractor $(\mathrm{H} 4)(10.1 \%)$, and for negative values, that it does so as the contractor and subcontractor (H6) (4.1\%); while for positive values of dimension 2, that the company works on the job as the developer, contractor and subcontractor (H7) $(3.8 \%)$, and for negative values, that it does so as the developer and contractor (H4) (1.0\%).

With regard to variable I, the category that best expresses for positive values in dimension 1 is that the company implements a prevention plan before starting the job (I1) $(32.8 \%)$, and for negative values that the company does not implement such a plan (I2) $(18.6 \%)$; while for positive values of dimension 2, that the company does not implement a prevention plan (I2) (12.0\%), and for negative values, that the company sometimes implements such a plan (I3) (1.8\%). For variable J, the category that best accounts for positive values in dimension 1 is that the company adopts personal and collective protection, color codes and signaling (J8) (15.5\%), and for negative values that they only adopt personal protection (J2) (5.2\%); for positive values in dimension 2, that they only adopt personal protection as a preventative work measure (J2) $(24.1 \%)$, while for negative values, that they adopt personal and collective protection and signaling (J5) (3.8\%) as preventative work measures.

Regarding variable $\mathrm{L}$, the category that best explains the positive values in dimension 1 is that the company gives training to new company personnel (L1) (58.5\%), and for negative values, that the company sometimes gives training to new company personnel (L3) (42.6\%); while for positive values for dimension 2, that the company does not give training to new company personnel (L2) $(1.8 \%)$; whereas for negative values, there is no category that discriminates well. For variable $M$, the category that best expresses the positive values in dimension 1 is that the company performs a medical and aptitude test on new company workers (M1) (37.6\%), and for negative values, that the company does not perform a medical and aptitude test on new workers (M2) (45.0\%); while for positive values for dimension 2, that the company likewise does not perform a medical and aptitude test on new company workers (M2) (7.7\%), and for negative values, that the company sometimes performs a medical and aptitude test on new company workers (M3) (10.6\%).

For variable $\mathrm{P}$, the category that best accounts for positive values in dimension 1 is that the company performs a risk and safety evaluation during the work's execution (P4) (6.8\%), and for negative values, that it carries out a risk and safety evaluation before starting the job (P1) (7.2\%); while for positive values of dimension 2, that the company does not respond to the question asking when it performed a risk and safety evaluation for the job (P7) (5.3\%), and for negative values, that it carried out a risk and safety evaluation before, during and at the end of the job (P5) (7.1\%). For variable $\mathrm{U}$, the category that best explains the positive values for dimension 1 is that the company installs toilets and hand-washing facilities on the job (U1) (59.5\%), and for negative values, that the company sometimes installs toilets and hand-washing facilities on the job (U3) (47.0\%); while for positive values for dimension 2, that the company does not install toilets and hand-washing facilities on the job (U2) $(14.3 \%)$, and for negative values, that the company sometimes installs toilets and hand-washing facilities on the job (U3) (2.8\%).

For variable $\mathrm{V}$, the category that best expresses the positive values for dimension 1 is that the company installs urinals on the worksite (V1) (63.0\%), and for negative values, that the company does not install urinals on the worksite (V2) (15.3\%); while for positive values for dimension 2, that the company does not install urinals on the worksite (V2) $(28.5 \%)$, and for negative values, that the 
company sometimes installs urinals on the worksite (V3) (18.6\%). For variable X, the category that best accounts for positive values for dimension 1 is that the company installs changing rooms on the worksite (X1) (57.9\%), and for negative values, that the company sometimes installs changing rooms on the worksite (X3) (14.7\%); while for positive values for dimension 2, that the company does not install changing rooms on the worksite (X2) (18.0\%), and for negative values, that the company sometimes installs changing rooms on the worksite (X3) (9.2\%).

For variable $Y$, the category that best explains the positive values for dimension 1 is that the company installs a lunch area on the worksite (Y1) (53.5\%), and for negative values that the company does not install a lunch area on the worksite (Y2) (18.6\%); while for positive values for dimension 2 , that the company does not install a lunch area on the worksite (Y2) $(28.4 \%)$, and for negative values, that the company sometimes installs a lunch area on the worksite (Y3) (36.3\%). For variable $Z$, the category that best expresses the positive values for dimension 1 is that the company indicates emergency routes and exits on the worksite (Z1) $(60.5 \%)$, and for negative values, that the company does not indicate emergency routes and exits on the worksite (Z2) (16.9\%); while for positive values for dimension 2, that the company does not indicate emergency routes and exits on the worksite (Z2) $(29.7 \%)$, and for negative values, that the company sometimes indicates emergency routes and exits on the worksite (Z3) $(25.9 \%)$.

For the variable $Z Z$, the category that best accounts for positive values in dimension 1 is that the company makes exclusive unloading zones available on the worksite (ZZ1) $(63.3 \%)$, and for negative values, that the company sometimes makes exclusive unloading zones available on the worksite (ZZ3) (22.9\%); while for positive values for dimension 2, that the company does not make exclusive unloading zones available on the worksite (ZZ2) $(7.7 \%)$, and for negative values, that the company sometimes makes exclusive unloading zones available on the worksite (ZZ3) (16.7\%). For variable II, the category that best accounts for positive values for dimension 1 is that the company installs safety networks on the worksite (II1) $(57.2 \%)$, and for negative values, that the company does not install safety networks on the worksite (II2) $(34.8 \%)$; while for positive values for dimension 2 , that the company does install safety networks on the worksite (II1) $(6.0 \%)$, and for negative values, that the company sometimes installs safety networks on the worksite (II3) (7.5\%).

For variable $\mathrm{KK}$, the category that best explains the positive values for dimension 1 is that the company considers aspects of ventilation on the worksite (KK1) $(59.7 \%)$, and for negative values, that the company does not consider aspects of ventilation on the worksite (KK2) (43.0\%); while for positive values for dimension 2, that the company does consider aspects of ventilation on the worksite (KK1) $(4.0 \%)$, and for negative values, that the company sometimes considers aspects of ventilation on the worksite (KK3) (10.6\%). For variable LL, the category that best expresses the positive values for dimension 1 is that the company considers aspects of noise protection on the worksite (LL1) (40.7\%), and for negative values, that the company does not consider aspects of noise protection on the worksite (LL2) (41.2\%); while for positive values for dimension 2, that the company does consider aspects of noise protection on the worksite (LL1) (5.6\%), and for negative values, that the company sometimes considers aspects of noise protection on the worksite (LL3) $(2.1 \%)$.

For variable SS, the category that best accounts for positive values for dimension 1 is that the company develops a Health and Safety Plan to execute work when working as the contractor (SS1) $(20.4 \%)$, and for negative values, that the company does not develop a Health and Safety Plan to execute work when working as the contractor (SS2) (23.2\%); while for positive values for dimension 2, that the company does not develop a Health and Safety Plan to execute work when working as the contractor (SS1) (17.2\%), and for negative values, that the company sometimes develops a Health and Safety Plan to execute work when working as the contractor (SS3) (28.1\%).

For variable TT, the category that best explains the positive values for dimension 1 is that the company develops a Health and Safety Plan to execute work when working as the contractor, based on the Health and Safety Study, which requires risk assessment and meetings being held with subcontractors (TT9) (4.1\%), and for negative values, that the company prepares a Health and Safety 
Plan to execute work based on other indeterminate things when working as the contractor (TT4) (1.5\%); while for positive values for dimension 2, that the company prepares a Health and Safety Plan to execute work when working as the contractor based on nothing (TT5) (0.3\%), and for negative values, that the company prepares a Health and Safety Plan to execute work when working as the contractor, based on the Health and Safety Study, which requires risk assessment and meetings being held with subcontractors (TT9) (10.8\%).

For variable AAA, the category that best expresses the positive values for dimension 1 is that the company holds health and safety meetings with the subcontractors to coordinate the work when working as the contractor (AAA1) (20.3\%), and for negative values, that the company does not hold health and safety meetings with the subcontractors to coordinate the work when working as the contractor (AAA2) $(23.2 \%)$; while for positive values for dimension 2 , that the company does not hold health and safety meetings with the subcontractors to coordinate the work when working as the contractor (AAA2) (5.6\%), and for negative values, that the company does hold health and safety meetings with the subcontractors to coordinate the work when working as the contractor (AAA1) $(16.0 \%)$.

For variable EEE, the category that best accounts for positive values for dimension 1 is that the company has a high awareness (EEE3) of suffering accidents in its construction processes $(3.6 \%)$, and for negative values, that the company has a low awareness (EEE1) of suffering accidents in its construction processes $(0.6 \%)$; while for positive values for dimension 2 , that the company has a medium awareness (EEE2) of suffering accidents in its construction processes $(2.1 \%)$, and for negative values, that the company has an awareness of suffering accidents in its construction processes that is both high (EEE3) $(0.2 \%)$ and low (EEE1) $(0.2 \%)$.

\subsubsection{Object Scoring (Companies)}

Finally, the MCA allows one to represent a factorial plane of the objects (companies) using each of their scores in each of the two dimensions (Figure 3). In this representation, one can observe how the companies in the sample are grouped into 4 clusters with homogenous characteristics. Cluster 1 presents positive scores in both dimensions, cluster 2 presents positive scores for dimension 1 and negative for dimension 2, cluster 3 presents negative scores in both dimensions and cluster 4 presents negative scores in dimension 1 and positive in dimension 2.

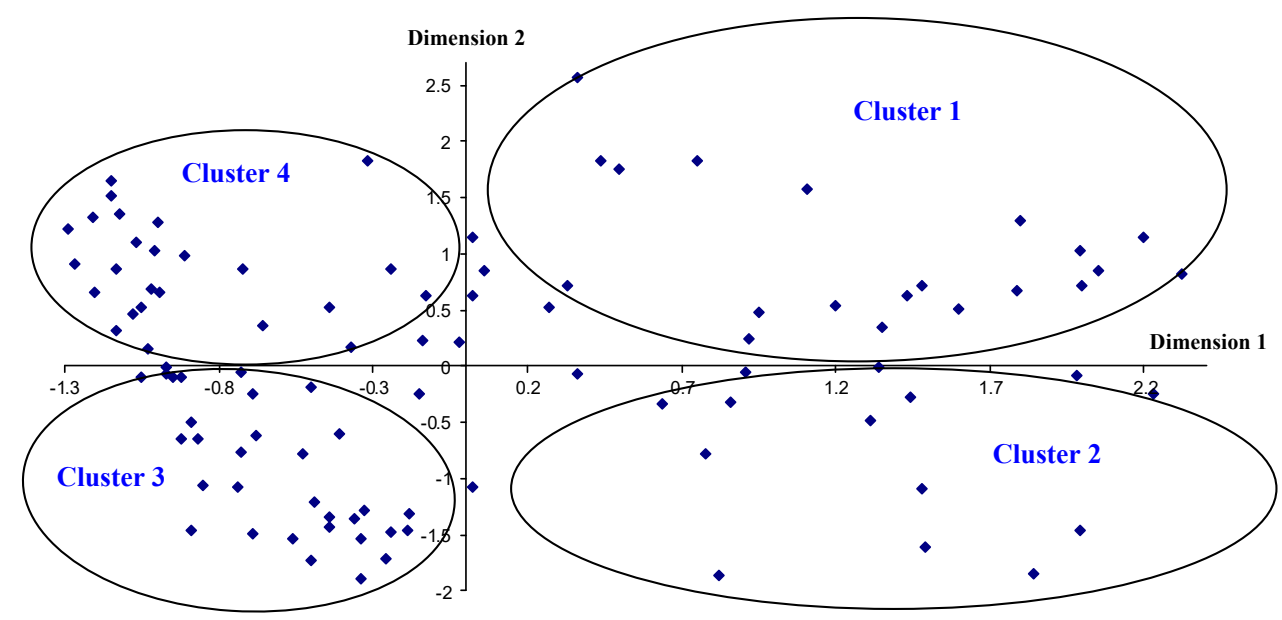

Figure 3. Factorial plane of the object scoring (companies).

\section{Discussion}

\subsection{Study Limitations}

For the characterization of workplace risk prevention in Guatemalan construction companies, a sample was considered containing 5.1\% of the Prequalified Companies in the census from the 
Guatemalan Ministry of Communications, Infrastructure and Housing in operation as of December 2015 [49]; thus, the present study is an estimation based on the companies in the sample, but this might be different for other companies.

\subsection{Descriptive Analysis of the Variables}

\subsubsection{Characterization of the General Company Variables}

Most of the construction companies in Guatemala (52.0\%) dedicate their activity simultaneously to civil engineering, building construction and other specialized construction, while $21.0 \%$ only participate in civil engineering and building construction (a value below the $38 \%$ of companies in the construction sector of Andalusia, Spain, that are dedicated to both activities [47]), 13\% only to building construction (a value below the 32\% of companies in the Andalusian construction sector that are dedicated to both activities [47]), and 11.0\% only to civil engineering (a value below $16 \%$ of companies in the Andalusian construction sector that are dedicated to both activities [47]). Regarding the Guatemalan departments (regional areas) where this activity takes place, their distribution varies greatly across the country: $26 \%$ of companies work all over the country, $17 \%$ in the Department of Guatemala REGION (I), another $17 \%$ in Departments of Guatemala REGION (I) together with Sacatepéquez, Escuintla, Chimaltenango, REGION IV, and $8 \%$ in the departments of Quetzaltenango, San Marcos, Totonicapán, Suchitepéquez, Retalhuleu, Sololá, REGION VI (see Figure 1). These data agree with the INE (Instituto Nacional de Estadística) statistics [49], which estimate that more than $50.0 \%$ of construction companies carry out activity in the Department of Guatemala.

Guatemalan construction companies have an average annual turnover (C) of 1.29 million euros (s.d. 6.29) such that $23.0 \%$ turnover between 0.3 and 0.5 million euros, $21.8 \%$ turnover between 0.1 and 0.3 million euros and $17.2 \%$ turn over less than 0.1 million euros. The average turnover obtained almost coincides with the average annual turnover of greenhouse construction companies in south-eastern Spain, which has been quantified at 1.56 million euros [48], such that $50 \%$ of these companies turnover less than one million euros and 30\% turn over more than 2 million euros. Likewise, for construction companies as a whole in Andalusia, 29.0\% of them turn over between 0.5 and 1 million euros [47]. The average number of company office workers (D) is 7.3 (s.d. 15.06), such that $61.2 \%$ have less than 6 office workers, 30.6\% have between 6 and 10, 6.1\% have between 11 and 20 and $2.1 \%$ have more than 20. The average number of on-site workers (E) is 81.1 (s.d. 75.22 ), such that $11.3 \%$ are microcompanies; that is to say, they have less than 11 workers (a very similar percentage to companies in the Andalusian construction sector as a whole, which is $14.0 \%$ [47]), and very far from the $50 \%$ of microcompanies in the greenhouse construction sector in south-eastern Spain [48]; while 39.2\% are small companies, having between 11 and 50 workers, which is somewhat less than the small construction companies in Andalusia, which is 54\% [47]. Finally, in Guatemala, the rest of the companies (49.5\%) are medium size, such that $17.5 \%$ have between 51 and 100 workers and $13.4 \%$ between 101 and 150 workers.

The average number of work crews per year (F) that make up Guatemalan construction companies is 6.8 (s.d. 5.55), a value above the 4.4 (s.d. 2.59) that is the average number of work crews making up greenhouse construction companies in south-eastern Spain [48]. This is logical given that the difference in the number of microcompanies that exist between the two sectors. Of Guatemalan construction companies, $41.7 \%$ have between 4 and 6 work crews, $22.9 \%$ between 7 and 10, and $22.9 \%$ with less than 4 work crews, while in the greenhouse construction sector in south-eastern Spain, $40.0 \%$ have less than 5 work crews [48]. Regarding the average number of years that the Guatemalan construction companies have carried out on-site works $(\mathrm{G})$, this amounts to 2.7 years (s.d. 0.55 ), such that $49.0 \%$ have been working for between 11 and 20 years, 32.7\% for less than 11 years and $15.3 \%$ for between 21 and 30 years.

Finally, $47.5 \%$ of Guatemalan construction companies work on jobs solely as contractors, while in the Andalusian construction sector, it is only 36.0\% [47], and in the greenhouse construction sector in south-eastern Spain [48], it is $80.0-25.2 \%$ as contractors and subcontractors, $16.0 \%$ in the Andalusian 
construction sector [47], 20.0\% in the greenhouse construction sector of south-eastern Spain [48], and $16.2 \%$ as developer, contractor and subcontractor.

4.2.2. Characteristics of the Prevention Activities and Health and Safety Management in the Companies and on the Building Sites

Currently, to achieve fewer accidents on construction sites, there has been for some time techniques for the prevention and management of workplace risks in construction companies via the design process $[14,16,32,34,35]$. Accordingly, $42.0 \%$ of companies reported that they carry out a prevention plan before starting a construction job and $43.0 \%$ do so sometimes. With regard to preventative measures adopted on site, $28.0 \%$ reported that they practice those of personal protection, collective protection and signaling at the same time, and another $28.0 \%$ only those of personal protection and signaling at the same time, with $19.0 \%$ that only practice those of personal protection. In comparison, the totality of companies in the greenhouse construction sector of south-eastern Spain confirmed that they adopt personal protection measures for workers but do not adopt those of collective protection and do not carry out on-site signaling [48]. 25.0\% of the Guatemalan construction companies that reported their workers adopting safety measures, do so for head, eye, hands and feet protection, and $10.0 \%$ for head, ear, eye, hand, nose, feet and face protection; while less than $56.0 \%$ reported that they protect their heads with safety helmets, the remaining $44.0 \%$ do not use them to protect their heads, a value that is significantly below that reported by Pérez-Alonso and collaborators for workers in the greenhouse construction sector in south-eastern Spain [48], which stated that $100.0 \%$ of workers do not use safety helmets; these data confirm the results obtained by Tam and collaborators for the construction sector in China [26], in which the workers in the sample reported that the safety helmet was not convenient for many operations. Likewise, in China, Chia-Fen and collaborators determined that the smallest construction companies presented a higher incidence of falls from heights owing to a lack of experience, of training and the generalized practice of not using personal or collective protection equipment [51]. In this regard, various authors have reported that not using personal or collective protection equipment is a major source of accidents in the construction sector [18,21,22]. Regarding the work clothing used by workers in Guatemalan construction, 37.0\% of companies reported that they use T shirts and hi-viz jackets, $16.0 \% \mathrm{~T}$ shirts, hi-viz jackets, and a uniform or canvas trousers, $14.0 \%$ use only hi-viz jackets and $12.0 \% \mathrm{~T}$ shirts and a uniform or canvas trousers. Therefore, on many occasions, the work clothing is inadequate, as described by Pérez-Alonso and collaborators in the greenhouse construction sector in the south-east of Spain [48]. Consequently, in these circumstances, unsatisfactory environmental conditions can be produced in the workplace, as confirmed by various authors, in such a way that small companies present worse workplace conditions and a greater risk of worker accidents [52-56].

Regarding health and safety training for the workers, Cheng and collaborators reported that it is fundamental to avoid accidents on the worksite [1], but that on many occasions the construction companies do not provide it sufficiently to reduce costs. In addition, not only this, there are companies, mostly microcompanies, that assume that the workers must know themselves what to do to avoid accidents in the building procedures that need to be developed on site [57]. In Guatemalan construction companies, $42.4 \%$ give training, $53.6 \%$ reported that they sometimes do, and the remaining $4 \%$ reported that they provide none; this results in a lack of safety [26], which contrasts with the current tendency where health and safety in the workplace is taught through design at the degree and postgraduate levels at universities [33]. However, in the greenhouse construction companies of south-eastern Spain [48], only 50.0\% carry out such training prior to work, a lower percentage to that determined by Calderón for Andalusian construction companies (Spain) [47], which was 62.5\%. Regarding the right that workers have to a medical assessment, only $12.4 \%$ of the sampled companies provide this, $15.4 \%$ do so sometimes, whereas $72.2 \%$ reported that they do not do so; these values differ greatly from the 70.0\% of greenhouse companies in south-eastern Spain [48] and the 86.0\% of Andalusian construction companies that provide it [47]. 
On the other hand, employers are obliged to perform an initial risk assessment as well as other periodical ones, as appropriate; hence $43.0 \%$ of sampled companies reported that they risk assess before starting the job, $22.0 \%$ before and during the job, and $16.0 \%$ during the job, and $13 \%$ before, during and at the end of the job, and only 3.0\% reported that they never do so; this last value is very small compared to the $30.0 \%$ reported by Pérez-Alonso and collaborators for greenhouse construction in the south-east of Spain [48]. Regarding how safety and risk control is carried out on the job, $56.6 \%$ of sampled companies only carry it out using a supervisor, $13.1 \%$ using a supervisor and a safety foreman, and $4.0 \%$ reported that they do not do so. The frequency with which the sampled companies verify the on-site risks and safety is, $22.0 \%$ at the start of a job, $19.0 \%$ at the beginning and the end of a job, and $19.0 \%$ at the start and daily. Accordingly, Goh and collaborators reported that exhaustive maintenance has to be performed along with periodic safety inspections [27], continuous safety training and the development of a plan to investigate accidents to prevent future injury; consequently, there are companies that not only possess such controls but that point them out as much as possible, in order to give them greater relevance among companies that work transparently and wish to gain greater legitimacy [58].

Continuing with the sampled companies, $28.0 \%$ reported that there is an entity that obliges them to control risks on site, while another $28.0 \%$ reported that there is not. When this entity exists, $59.0 \%$ report that it is the contractor or developer, $18.1 \%$ that it is the Ministry of Work and $8.2 \%$ that it is the Social Security Institute. Safety is a process that considers the use of all types of equipment and techniques to systematically guarantee the well-being of the workers [23-25]; therefore, the control of equipment and machinery by the company within the prevention management framework is important. Therefore, for companies in the Guatemalan construction sector, 18.0\% reported that they do have an operation manual available for tools and equipment, $58.0 \%$ reported that they sometimes have one available for some of them, and $24.0 \%$ reported that one does not exist. $45.0 \%$ have a tool and equipment inventory available while $20.0 \%$ do not. Likewise, $31.0 \%$ give training on tool and equipment use while $23.0 \%$ reported that they do not. With respect to the control of equipment handed to the workers, $34.3 \%$ of sampled companies do control the equipment provided with a loading and unloading card while $35.4 \%$ do not. $22.2 \%$ of companies make an operation manual for their machinery available while $13.1 \%$ do not. In addition, for handling this machinery, $39.4 \%$ of companies reported that they do give training on how to use it while $13.1 \%$ do not. Similarly, $64.0 \%$ of companies reported that they make first-aid equipment available as well as personal training on how to use it while $30.0 \%$ said they do so sometimes, and $6.0 \%$ said that they do not. As a comparison to all the prevention management indicators detailed in the present paragraph, in greenhouse construction companies in south-eastern Spain [48], 50.0\% make a work equipment identification list available while the other $50.0 \%$ do not; and regarding the existence of an equipment maintenance $\log , 60.0 \%$ of these companies make them available.

Recently, passive safety indicators have begun to be implemented that formulate specific programs and political strategies; for example, in Tennessee (USA), the most popular safety indicators proposed were housekeeping, the use of PPE and substance abuse [59], affirming moreover, that the largest companies are most likely to use the safety indicators than are smaller companies. In this context, and in relation to on-site hygiene, health, and safety measures in Guatemalan construction companies, they indicated that $51.0 \%$ of them make a place available on site to dispose of waste or rubbish, $42.0 \%$ sometimes do and $7.0 \%$ do not. $49.0 \%$ of the companies indicated that they carry out general site cleaning daily, $41.8 \%$ do so once a week and $3.3 \%$ do so on demand. Regarding the toilet facilities provided on site for the workers, $40.0 \%$ indicated that they provide toilet paper and bars of soap, or soap powder, $18.6 \%$ provide toilet paper, bars of soap or soap powder, and paper or cloth towels, while $17.1 \%$ only provide toilet paper and $8.6 \%$ only provide bars of soap or soap powder. Likewise, $42.3 \%$ install on-site toilets, $46.4 \%$ indicated that sometimes they do so and $11.3 \%$ say that they do not. Regarding whether they install urinals, $40.4 \%$ say they do not, $30.9 \%$ indicated that they do and $28.7 \%$ said they do so sometimes. Only $20.8 \%$ indicated that they install emergency showers on site, $47.9 \%$ do 
not and $31.3 \%$ said they do so sometimes. Regarding installing on-site changing rooms for workers, only $26.3 \%$ indicated that they do, while $42.1 \%$ do not, and $31.6 \%$ indicated that they do so sometimes. Conversely, $40.0 \%$ of sampled companies plan specific zones for offloading on site, while $17.0 \%$ do not and $43.0 \%$ do so sometimes. Only $25.0 \%$ of companies indicated that they install on-site safety networks, while $40.0 \%$ do not. As to whether the companies consider on-site lighting, $37.4 \%$ indicated that they do, while $10.1 \%$ said they do not. Concerning on-site ventilation, $56.6 \%$ said they do not provide it while only $24.2 \%$ said they do. With respect to on-site noise protection, only $16.3 \%$ indicated that they provide protection while $58.2 \%$ said they do not. Likewise, $41.7 \%$ indicated that they install electric cabling protection on site while $20.8 \%$ said they do not.

Regarding prevention management related to actions and communications in case of on-site accidents, one must emphasize that $92.0 \%$ of companies indicated that they do have procedures available in the case of on-site accidents, with the remaining $8.0 \%$ do not have any. Regarding where the victim of an accident is treated if an accident occurs, $25.8 \%$ of sampled companies indicated that it is the infirmary, health center, public hospital, Guatemalan Social Security Institute, or private hospital closest to the worksite, with $9.7 \%$ stating the nearest infirmary, public hospital, or Guatemalan Social Security Institute. $42.3 \%$ of the companies indicated that they do not communicate the accidents suffered on site with any entity, while only $13.4 \%$ said that they do, and of these, if they do so, $71.4 \%$ contact the contractor or the developer, while $12.2 \%$ contact the contractor or developer and the Guatemalan Social Security Institute, with $6.1 \%$ only notifying the Guatemalan Social Security Institute. Finally, with respect to the awareness of accident risk presented by the Guatemalan construction companies, they indicated that $63.0 \%$ consider there is a low probability of suffering worksite accidents, $33 \%$ considered it a medium probability and the remaining $4 \%$ considered it a high risk. This large percentage of companies that had a low probability perception of on-site accident risk is a clear indication of the limited risk management and training in those companies, as cited by Rodríguez-Garzón and collaborators [60,61], who stated that the companies presuppose that risk awareness should be something innate to the worker.

To summarize the issue at hand, one must point out that a high percentage of Guatemalan construction companies $(72.2 \%)$ do not perform medical assessments on their workers, and also a medium percentage of companies do not practice tool, machinery and equipment control, nor give specific training for operating the type of apparatus used on worksites, all of which demonstrates insufficient safety management $[27,47,48]$, owing to a company lacking a safety policy, that in turn, can lead to a higher level of accidents [26-28,30,47,48,54].

\subsubsection{Characteristics of the Health and Safety Activities That Contractors Take Part in on the Worksite}

According to several authors $[5,16,33,47,48]$, building work ought to be carried out following a technical project prepared by a competent technician, which includes a Health and Safety Study for the work to be done- this then becomes a worksite Health and Safety Plan as soon as work begins, which the contractor should propose to the works management and the Health and Safety Coordinator. For those Guatemalan construction companies that said they operated as contractors, only $13.4 \%$ reported that they prepare this Health and Safety Plan, 34.2\% do not prepare one and $52.4 \%$ do so sometimes; data which differ greatly from those reported by Calderón regarding Andalusian construction companies (Spain) [47], in which 95.0\% said they prepare a Health and Safety Plan, while only 3.3\% do not. Nonetheless, the Guatemalan data are better than those reported by Pérez-Alonso and collaborators [48], regarding greenhouse construction companies in south-eastern Spain, in which none of the companies prepared such a plan.

In addition, the comparison of the study results with those obtained by Calderón for the Andalusian construction industry (Spain) [47] continues. The last results are expressed in parentheses. When Guatemalan construction companies that work as contractors were asked how they prepare the worksite Health and Safety Plan, 38.6\% reported they do so through prior meetings with the subcontractors, $12.3 \%$ base it on the Health and Safety Study $(86.7 \%)$, and $7.0 \%$ base it on the Health 
and Safety Study as well as asking for a risk assessment from the subcontractors with prior meetings, while $5.2 \%$ base it on the Health and Safety Study and prior meetings with the subcontractors. Regarding whether the stipulations proposed by the Health and Safety Plan are complied with on the job, only $20.3 \%$ reported that they always are $(71.0 \%)$, while $17.6 \%$ never, and $62.2 \%$ only partially. Regarding whether the contractors send a copy of the Health and Safety Plan to the subcontractors, $14.9 \%$ reported that they do $(93.5 \%)$ while $41.9 \%$ reported that they do not and $43.2 \%$ that they do so only sometimes. Likewise, $42.1 \%$ of companies who operated as contractors indicated that they know the worksite Health and Safety Coordinator, while $57.9 \%$ said they do not; this contrasts with the $100 \%$ that stated that they know them for construction companies in Andalusia [47]. Regarding the frequency of visits by the Health and Safety Coordinator to the worksite, $21.1 \%$ of sampled companies who work as contractors reported that this is once or twice a week (39.3\%), $15.8 \%$ said it is once a fortnight $(25.0 \%)$, $5.3 \%$ once a week and $7.9 \%$ indicated that they do not know (10.7\%). Regarding who pays the Health and Safety Coordinator's fee, $44.9 \%$ of the sampled companies who act as the contractor reported that they pay themselves (43.7\%), 32.7\% reported that the developer pays and $22.4 \%$ said it is the contractor and the developer. Likewise, $16.2 \%$ of sampled companies reported that the developer evaluates the health and safety measures that the contractor company will undertake when awarding the work (28.1\%), while $29.7 \%$ reported that the developer does not evaluate such measures and $54.1 \%$ that they sometimes do so $(43.8 \%)$. Regarding whether the company acting as the contractor hold safety meetings with the subcontractors to disclose the progress and incidents of on-site safety conditions, only $15.2 \%$ of companies indicated that they do $(41.4 \%)$, while $46.8 \%$ reported that they do not $(6.9 \%)$, and the remaining $38.0 \%$ do so sometimes (51.7\%). With respect to whether it would be of interest to classify contractor companies based on the quality and management of workplace risk prevention in order to improve on-site safety conditions, $51.8 \%$ of the sampled contractor companies indicated that such a classification is necessary $(71.9 \%)$, while only $2.5 \%$ said that it would not be $(9.3 \%)$, and the remaining $45.7 \%$ said that it probably would be necessary (18.8\%). Finally, $10.0 \%$ of the sampled contractor companies indicated that when they subcontract a job, they evaluate the subcontractor based on their level of safety (32.3\%), while $42.5 \%$ said they do not $(19.3 \%)$, and $47.5 \%$ that they do so sometimes $(48.4 \%)$.

The low percentages of contractor companies that said they prepare a Health and Safety Plan (13.4\%) and comply on site with the stipulations it contains $(20.3 \%)$ reveals a lack of safety $[5,8,16,26,47,48]$, which, in turn, results in a greater incidence of accidents $[5,8,16,28,47,48]$. All of this is due to the absence of a clear safety policy in Guatemalan construction companies, and as indicated by Hasle and collaborators [54], the companies do not consider safety a priority.

\section{3. $M C A$}

Interpreting the factorial planes in Figures 2 and 3, one can observe the correspondences between the categories of variables and thus the characterization of each of the 4 clusters of specific companies. Both companies in cluster 1 and in cluster 2 have the categories that nullify, or practically nullify the quantification in dimension 2 of the following variables: they do develop a prevention plan at the start of the work (I1); they give workplace prevention training to the workers (L1); they install toilets (U1), urinals (V1), emergency showers (W1), changing rooms (X1), on-site emergency routes (Z1) and they do know an entity that obliges them to control on-site health and safety (GG1). On the other hand, companies in cluster 1 are characterized by presenting all the categories of variables with positive quantifications in dimensions 1 and 2, the most significant being that the companies only work on civil engineering construction (A1), or only on building construction (A2), or both activities at the same time (A4); that present a medium awareness of suffering some worksite accidents (EEE2); that operate on jobs solely as the developer (H1), or solely as the subcontractor (H3), or at the same time as the developer, contractor and subcontractor (H7); that their turnover is less than 0.1 million euros (C1); that the number of on-site workers is less than 11 (E1) or between 11 and 50 (E2); that the number of work crews is less than 4 (F1); that they adopt only collective protection as on-site 
preventative measures (J1), or on-site collective protection and signaling (J11), or personal protection and color coding (J12), or collective protection and personal protection (J13); that they perform medical assessments on the workers (M1); that they install an on-site lunch area (Y1); that they establish a specific on-site unloading zone (ZZ1); that they perform on-site risk assessment during the work (P4), at the end of the work (P8), or never (P6), or that they do not respond to the question (P7); that they carry out an equipment inventory (BB1); that they give equipment-handling training (CC1); that they place safety networks on site (II1); that they use on-site lighting when necessary (JJ1); that they use on-site ventilation when necessary (KK1); and that they use on-site acoustic protection (LL1).

Companies in cluster 2 are characterized by presenting all the categories of variables with positive quantifications in dimension 1 but negative in dimension 2 . The most significant are that the company works on site as the developer or as the contractor (H4); that it turns over between 1 and 2 million euros (C6), or between 2 and 10 million euros (C7) or more than 10 million euros (C8); that the number of on-site workers is between 151 and 200 (E5) or more than 200 (E6); that the number of work crews is more than 20 (F5); that they adopt collective protection, personal protection, color coding and signaling as on-site prevention measures (J8), or as above but without collective protection (J6); that they sometimes carry out medical assessments on the workers (M3); that they carry out on-site risk assessment before and during a job (P2), or before, during and at the end of a job (P5); that they sometimes have acoustic protection on site (LL3); that they prepare a Health and Safety Plan (SS1); that they prepare the Health and Safety Plan based on a risk assessment requested only from the subcontractors (TT2) or on the Health and Safety Study with prior meetings held with the subcontractors (TT6), or that they request a risk assessment from the subcontractors and hold prior meetings with the subcontractors (TT8), or they base it on the Health and Safety Study, request a risk assessment from the subcontractors as well as prior meetings with the subcontractors (TT9), or on the Health and Safety Study, request a risk assessment from the subcontractors as well as prior meetings with the subcontractors and others (TT10), and that they know the Health and Safety Coordinator for the job (WW1); and finally that they present a high awareness of suffering some worksite accidents (EEE3).

The companies in cluster 3 are characterized by presenting all the categories of the variables with negative quantifications in dimensions 1 and 2, the most significant are that the companies construct in the 3 activities, civil engineering, building construction and specialized construction (A7); that they work on jobs solely as contractors (H2); that they turn over between 0.5 and 0.7 million euros (C4) or between 0.7 and 1.0 million euros (C5); that the number of workers on site is between 101 and 150 (E4); that the number of work crews is between 7 and 10 (F3) or between 11 and 20 (F4); that as on-site preventative measures, they adopt either collective and personal protection and signaling (J5), or personal protection and on-site signaling (J7); that sometimes on site they install toilets (U3), urinals (V3), showers (W3), changing rooms (X3), a lunch area (Y3), emergency routes (Z3) and unloading zones (ZZ3); that they perform an on-site risk assessment during and at the end of the job (P3); that they sometimes carry out an equipment inventory (BB3); that they sometimes give equipment-handling training (CC3); that they sometimes know an entity that obliges them to control on-site health and safety (GG3); that they sometimes locate safety networks on site (II3); that they sometimes use lighting on site when it is necessary (JJ3); that sometimes they have ventilation on site when necessary (KK3); that they sometimes prepare an on-site Health and Safety Plan (SS3), that the Health and Safety Plan is based on the Health and Safety Study (TT1) or on others (TT4); that sometimes they hold health and safety meetings with the subcontractors when they act as contractors on the job (AAA3).

The companies in cluster 4 are characterized as presenting all the categories of variables with negative quantifications in dimension 1 and positive quantifications in dimension 2, the most significant are that they only construct specialized buildings (A3), or civil engineering and specialized constructions (A5); that they work on jobs solely as contractors and subcontractors (H6); that they turn over between 0.1 and 0.3 million euros (C2), or between 0.3 and 0.5 million euros (C3); that the number of on-site worker is between 51 and 100 (E3); that the number of work crews is between 4 and 
6 (F2); that they do not prepare an on-site prevention plan (I2); that they adopt on-site preventative measures only for personal protection (J2); that they do not give workplace prevention training to their workers (L2); that they do not perform medical assessments on their workers (M2); that they do not install toilets on site (U2), or urinals (V2), or showers (W2), or changing rooms (X2), or a lunch area (Y2), or emergency routes (Z2), or unloading zones (ZZ2); that they perform a risk assessment before the start of the job (P1); that they do not perform an equipment inventory (BB2); that they do not give equipment-handling training (CC2); that they do not know an entity that obliges them to control on-site health and safety (GG2); that they do not place safety networks on site (II2); that they do not use on-site lighting (JJ2); that they do not use ventilation on site when it is necessary (KK2); that they do not prepare an on-site Health and Safety Plan (SS2); that they base their Health and Safety Plan on nothing (TT5); that they do not know the on-site Health and Safety Coordinator (WW2), and that they do not hold health and safety meetings with the subcontractors when they act as contractors on the job (AAA2).

Likewise, both the companies in cluster 3 and those in cluster 4 present the categories that make quantification null in dimension 2, or practically null, for the following variables: that they sometimes give workplace prevention training to their workers (L3); that they do not practice on-site acoustic protection (LL2), and finally, that they present a low awareness of suffering any workplace accidents (EEE3).

Of the characteristics described in the four clusters regarding Guatemalan construction companies, one can clearly observe that the larger companies (higher turnover, more on-site workers and more work crews) are those that adopt better preventative measures and Health and Safety Management in the company and on site in the different activity areas $[26,28,30,48,51,57,60,61]$, so that the largest correlate with a high awareness of suffering on-site accidents while those of medium size have a lower awareness of suffering workplace accidents, and they consider it to be medium, as other authors have confirmed about the construction sector in other countries, while the smaller companies present worse physical conditions in the workplace and a higher risk of accidents for their workers $[18,48,52-57,60,61]$.

\subsection{Recommendations}

According to everything discussed, the following recommendations are proposed to improve the accidents prevention in the companies of the Guatemalan construction industry, especially the small and medium ones:

- Make a great effort to increase training in matters of safety and health prevention of their managers and workers, as well as the entrepreneurs themselves.

- Adopt as a priority, perform medical examinations to their workers, both when joining the company, and through their professional career in it.

- Implement a mandatory risk assessment in all phases of the construction works.

- Establish operating manuals for tools, equipment, and machinery, carrying out an inventory and providing training in their management.

- Provide work clothes that are better suited to the task developed by the worker.

- Communicate compulsorily the accidents suffered in the company with the periodicity established by the competent authority.

- Increase the use and compliance of Safety and Health Plans in the construction works.

- Promote the participation of safety and health coordinators in the design, planning and execution of the construction works.

Likewise, it would be advisable that the competent labor administration of Guatemala:

- Complement the existing labor legislation for the construction industry, to ensure adequate prevention and risk management in these companies.

- Promote educational plans for all professionals involved in construction works that incorporate a minimum of mandatory training in safety and health. 
- Promote economic aid and/or tax incentives to companies, so that they adopt appropriate safety and health practices, checking and certifying that they perform it.

\section{Conclusions}

The present study investigated the characterization of the occupational risk prevention in the Guatemalan construction industry, correlating parameters of the prevention activity and occupational risk management with structural and organizational parameters of the companies. It was carried out using the simple random sampling technique and a questionnaire developed for it.

As a whole, the companies studied in the Guatemalan construction sector are characterized as operating mostly $(52.0 \%)$ in civil engineering work, building construction and other specialized construction, and that they work mostly as contractors (47.5\%). Likewise, they are characterized as being medium-sized companies, with an average of 81.1 on-site workers per year, having an average of 6.8 on-site work crews annually and an average annual turnover of 1.29 million euros.

By means of the multivariate technique of MCA, it has been possible to group companies in the Guatemalan construction industry into 4 clusters, with homogeneous characteristics, so that the larger construction companies (larger turnover, more on-site workers, and more work crews) adopt better preventative measures and Health and Safety Management, both on site and in the company as a whole, in such a way that the largest are correlated with a high awareness of suffering on-site accidents, while those of medium size have a medium awareness. In contrast, companies with a small number of workers more poorly manage workplace risk prevention, with a low awareness of accident risk, which is typical of a low level of prevention management.

Recommendations have been proposed to construction companies and the competent labor administration in Guatemala to improve accident prevention.

Author Contributions: Conceptualization, F.A.H.-A.; Methodology, F.A.H.-A., J.P.-A. and F.S.; Software, F.A.H.-A. and J.P.-A.; Validation, J.P.-A. and F.S.; Formal Analysis, F.A.H.-A. and J.P.-A.; Investigation, F.A.H.-A. and J.P.-A.; Resources, F.A.H.-A., M.G.-G. and F.S.; Data Curation, F.A.H.-A. and J.P.-A.; Writing-Original Draft Preparation, F.A.H.-A.; Writing-Review \& Editing, F.A.H.-A., J.P.-A., M.G.-G. and F.S.; Visualization, F.A.H.-A., J.P.-A., M.G.-G. and F.S.; Supervision, F.A.H.-A. and J.P.-A.; Project Administration, J.P.-A.

Funding: This research received no external funding.

Acknowledgments: The authors of the present study would like to thank all the Guatemalan construction companies that participated in the sampling phase for their valuable collaboration in responding to the questionnaires.

Conflicts of Interest: The authors declare no conflict of interest.

\section{Appendix A}

Table A1. Nomenclature and frequency of the categories of general company variables.

\begin{tabular}{ccc}
\hline Variable/Category Codes & Variables/Category of Variables & Frequency (\%) \\
\hline A & Construction activity & 100.0 \\
A1 & Only civil engineering & 11.0 \\
A2 & Only building construction & 13.0 \\
A3 & Only specialized construction & 2.0 \\
A4 & Civil engineering and building construction & 21.0 \\
A5 & Civil engineering and specialized construction & 1.0 \\
A6 & Construction of building and specialized construction & 0.0 \\
A7 & Civil engineering, building and specialized construction & 52.0 \\
\hline B & Guatemalan departments where the work is carried out $\mathbf{1}^{-0}$ & 100.0 \\
\hline B4 & Throughout the country & 26.0 \\
\hline B9 & Quetzaltenango, San Marcos, Totonicapán, Suchitepéquez, & 8.0 \\
\hline
\end{tabular}


Table A1. Conts.

\begin{tabular}{|c|c|c|}
\hline Variable/Category Codes & Variables/Category of Variables & Frequency $(\%)$ \\
\hline B13 & $\begin{array}{c}\text { Guatemala REGION I, Sacatepéquez, Escuintla, } \\
\text { Chimaltenango. REGION IV }\end{array}$ & 17.0 \\
\hline B18 & Guatemala REGION I & 17.0 \\
\hline $\mathrm{C}$ & Annual company turnover $(€)$ & 87.0 \\
\hline $\mathrm{C} 1$ & $<100,000$ & 17.2 \\
\hline $\mathrm{C} 2$ & $100,001-300,000$ & 21.8 \\
\hline $\mathrm{C} 3$ & $300,001-500,000$ & 23.0 \\
\hline $\mathrm{C} 4$ & $500,001-700,000$ & 12.6 \\
\hline $\mathrm{C} 4$ & $700,001-1,000,000$ & 11.5 \\
\hline C6 & $1,000,001-2,000,000$ & 8.0 \\
\hline $\mathrm{C} 7$ & $2,000,001-10,000,000$ & 4.6 \\
\hline $\mathrm{C} 8$ & $>10,000,000$ & 1.1 \\
\hline $\mathbf{D}$ & Number of office workers in the company & 98.0 \\
\hline D1 & $<6$ & 61.2 \\
\hline D2 & $6-10$ & 30.6 \\
\hline D3 & $11-20$ & 6.1 \\
\hline D4 & $>20$ & 2.1 \\
\hline $\mathbf{E}$ & Number of on-site workers in the company & 97.0 \\
\hline E1 & $<11$ & 11.3 \\
\hline E2 & $11-50$ & 39.2 \\
\hline E3 & 51-100 & 17.5 \\
\hline E4 & $101-150$ & 13.4 \\
\hline E5 & $151-200$ & 11.3 \\
\hline E6 & $>200$ & 7.2 \\
\hline $\mathbf{F}$ & Number of work crews annually & 96.0 \\
\hline F1 & $<4$ & 22.9 \\
\hline $\mathrm{F} 2$ & $4-6$ & 41.7 \\
\hline F3 & $7-10$ & 22.9 \\
\hline $\mathrm{F} 4$ & $11-20$ & 10.4 \\
\hline F5 & $>20$ & 2.1 \\
\hline G & Years working on site & 98.0 \\
\hline G1 & $0-10$ & 32.7 \\
\hline G2 & $11-20$ & 49.0 \\
\hline G3 & $21-30$ & 15.3 \\
\hline G4 & $31-40$ & 2.0 \\
\hline G5 & $>40$ & 1.0 \\
\hline $\mathbf{H}$ & Work on the job & 99.0 \\
\hline $\mathrm{H} 1$ & Only as the developer & 2.0 \\
\hline $\mathrm{H} 2$ & Only as the contractor & 47.5 \\
\hline H3 & Only as the subcontractor & 2.0 \\
\hline $\mathrm{H} 4$ & As developer and contractor & 7.1 \\
\hline H5 & As developer and subcontractor & 0.0 \\
\hline H6 & As contractor and subcontractor & 25.2 \\
\hline $\mathrm{H} 7$ & As developer, contractor, and subcontractor & 16.2 \\
\hline
\end{tabular}

\footnotetext{
${ }^{1}$ The other categories were not included as many were not representative.
} 
Table A2. Nomenclature and frequency of the categories of variables for Prevention Activities and Health and Safety Management in the company and on site (1st part).

\begin{tabular}{|c|c|c|}
\hline Variable/Category Codes & Variables/Category of Variables & Frequency $(\%)$ \\
\hline I & Execute prevention plan before starting the job & 100.0 \\
\hline I1 & Yes & 42.0 \\
\hline $\mathrm{I} 2$ & No & 15.0 \\
\hline I3 & Sometimes & 43.0 \\
\hline $\mathbf{J}$ & Preventative measures adopted on site ${ }^{1}$ & 100.0 \\
\hline $\mathrm{J} 1$ & Only collective protection & 3.0 \\
\hline $\mathrm{J} 2$ & Only personal protection & 19.0 \\
\hline J5 & Collective and personal protection plus signaling & 28.0 \\
\hline J6 & Personal protection, color coding plus signaling & 3.0 \\
\hline J7 & Personal protection plus signaling & 28.0 \\
\hline $\mathrm{J} 8$ & $\begin{array}{c}\text { Collective and personal protection, color coding plus } \\
\text { signaling }\end{array}$ & 14.0 \\
\hline $\mathrm{J} 11$ & Collective protection and signaling & 1.0 \\
\hline $\mathrm{J} 12$ & Personal protection and color coding & 2.0 \\
\hline $\mathrm{J} 13$ & Collective and personal protection & 2.0 \\
\hline $\mathbf{K}$ & Types of personal protection adopted on site ${ }^{1}$ & 100.0 \\
\hline K13 & $\begin{array}{l}\text { Head, ear, eye, hand, nose, feet, and face protection as well } \\
\text { as fall protection (harness) }\end{array}$ & 10.0 \\
\hline K18 & $\begin{array}{l}\text { Head, eye, hand, and feet protection as well as fall } \\
\text { protection (harness) }\end{array}$ & 8.0 \\
\hline K19 & $\begin{array}{l}\text { Head, eye, ear, hand, nose, and feet protection as well as fall } \\
\text { protection (harness) }\end{array}$ & 6.0 \\
\hline K22 & $\begin{array}{l}\text { Head, eye, ear, hand, nose, feet, face, and skin protection as } \\
\text { well as fall protection (harness) }\end{array}$ & 7.0 \\
\hline K29 & $\begin{array}{l}\text { Head, ear, eye, hand, nose, feet, and face protection as well } \\
\text { as fall protection (harness) }\end{array}$ & 25.0 \\
\hline $\mathbf{L}$ & Training given to workers on health and safety & 99.0 \\
\hline L1 & Yes & 42.4 \\
\hline L2 & No & 4.0 \\
\hline L3 & Sometimes & 53.6 \\
\hline $\mathbf{M}$ & Medical assessments carried out on the workers & 97.0 \\
\hline M1 & Yes & 12.4 \\
\hline M2 & No & 72.2 \\
\hline M3 & Sometimes & 15.4 \\
\hline $\mathbf{N}$ & Modality of on-site safety and risk control ${ }^{1}$ & 99.0 \\
\hline N1 & Supervisor & 56.6 \\
\hline N2 & Employer assumes responsibility for prevention & 6.1 \\
\hline N3 & Supervisor and safety manager & 13.1 \\
\hline N7 & No modality & 4.0 \\
\hline N8 & Other modalities & 3.0 \\
\hline N9 & Safety manager & 3.0 \\
\hline N14 & $\begin{array}{l}\text { Supervisor, safety manager, design group or commission } \\
\text { and in-house permanent service }\end{array}$ & 3.0 \\
\hline $\mathbf{O}$ & How often are on-site risks and safety verified & 100.0 \\
\hline O1 & At the beginning & 22.0 \\
\hline $\mathrm{O} 2$ & Daily & 11.0 \\
\hline O3 & Weekly & 7.0 \\
\hline $\mathrm{O} 4$ & At the end & 3.0 \\
\hline O5 & Never & 7.0 \\
\hline
\end{tabular}


Table A2. Cont.

\begin{tabular}{ccc}
\hline Variable/Category Codes & Variables/Category of Variables & Frequency (\%) \\
\hline O & How often are on-site risks and safety verified & 100.0 \\
O6 & At the beginning and at the end & 19.0 \\
O7 & At the beginning and weekly & 11.0 \\
O8 & At the beginning and daily & 19.0 \\
O9 & At the beginning, weekly and at the end & 1.0 \\
P & When is the on-site risk assessment carried out & 100.0 \\
P1 & Before starting the work & 43.0 \\
P2 & Before starting and during the work & 22.0 \\
P3 & During and at the end of the work & 1.0 \\
P4 & During the work & 16.0 \\
P5 & Before starting, during and at the end of the work & 13.0 \\
P6 & Never & 3.0 \\
P7 & Before starting and at the end of the work & 1.0 \\
P8 & At the end & 1.0 \\
\hline
\end{tabular}

${ }^{1}$ The other categories were not included as many were not representative.

Table A3. Nomenclature and frequency of the categories of variables for Prevention Activities and Health and Safety Management in the company and on site (2nd part).

\begin{tabular}{|c|c|c|}
\hline Variable/Category Codes & Variables/Category of Variables & Frequency $(\%$ \\
\hline Q & First-aid equipment available and personnel trained to use it & 100.0 \\
\hline Q1 & Yes & 64.0 \\
\hline Q2 & No & 6.0 \\
\hline Q3 & Sometimes & 30.0 \\
\hline $\mathbf{R}$ & A place is available on site to discard waste and rubbish & 100.0 \\
\hline R1 & Yes & 51.0 \\
\hline R2 & No & 7.0 \\
\hline R3 & Sometimes & 42.0 \\
\hline S & Frequency of general cleaning carried out on site & 91.0 \\
\hline S1 & Daily & 54.9 \\
\hline S2 & Once a week & 41.8 \\
\hline S3 & On demand & 3.3 \\
\hline $\mathrm{T}$ & Toilet facilities provided on site ${ }^{1}$ & 70.0 \\
\hline $\mathrm{T} 1$ & Toilet paper and bars of soap or soap powder & 40.0 \\
\hline $\mathrm{T} 2$ & Bars of soap or soap powder & 8.6 \\
\hline T5 & Toilet paper & 17.1 \\
\hline $\mathrm{T} 7$ & Toilet paper, bars of soap or soap powder, and paper or cloth towels & 18.6 \\
\hline T9 & $\begin{array}{c}\text { Toilet paper, bars of soap or soap powder, paper or cloth towels, } \\
\text { and sponge or brush for the skin }\end{array}$ & 7.1 \\
\hline $\mathbf{U}$ & Toilets installed on site & 97.0 \\
\hline U1 & Yes & 42.3 \\
\hline U2 & No & 11.3 \\
\hline U3 & Sometimes & 46.4 \\
\hline V & Urinals installed on site & 94.0 \\
\hline V1 & Yes & 30.9 \\
\hline V2 & No & 40.4 \\
\hline V3 & Sometimes & 28.7 \\
\hline $\mathbf{W}$ & Emergency showers installed on site & 96.0 \\
\hline W1 & Yes & 20.8 \\
\hline W2 & No & 47.9 \\
\hline W3 & Sometimes & 31.3 \\
\hline
\end{tabular}


Table A3. Cont.

\begin{tabular}{|c|c|c|}
\hline Variable/Category Codes & Variables/Category of Variables & Frequency $(\%)$ \\
\hline $\mathrm{X} 1$ & Yes & 26.3 \\
\hline $\mathrm{X} 3$ & Sometimes & 31.6 \\
\hline $\mathbf{Y}$ & Lunch area installed on site & 98.0 \\
\hline $\mathrm{Y} 2$ & No & 46.9 \\
\hline $\mathrm{Y} 3$ & Sometimes & 31.6 \\
\hline $\mathrm{Z}$ & Emergency routes installed on site & 99.0 \\
\hline Z1 & Yes & 30.3 \\
\hline $\mathrm{Z} 2$ & No & 35.4 \\
\hline ZZ1 & Yes & 40.0 \\
\hline $\mathrm{ZZ2}$ & No & 17.0 \\
\hline ZZ3 & Sometimes & 43.0 \\
\hline
\end{tabular}

${ }^{1}$ The other categories were not included as many were not representative.

Table A4. Nomenclature and frequency of the categories of variables for Prevention Activities and Health and Safety Management in the company and on site (3rd part).

\begin{tabular}{|c|c|c|}
\hline Variable/Category Codes & Variables/Category of Variables & Frequency $(\%)$ \\
\hline AA & A tool and equipment operating manual exists & 100.0 \\
\hline AA1 & Yes & 18.0 \\
\hline AA2 & No & 24.0 \\
\hline AA3 & Some & 58.0 \\
\hline BB & A tool and equipment inventory exists & 100.0 \\
\hline BB1 & Yes & 45.0 \\
\hline BB2 & No & 20.0 \\
\hline BB3 & Sometimes & 35.0 \\
\hline $\mathrm{CC}$ & Tool and equipment-handling training is given & 100.0 \\
\hline $\mathrm{CC} 1$ & Yes & 31.0 \\
\hline $\mathrm{CC} 2$ & No & 23.0 \\
\hline $\mathrm{CC} 3$ & Sometimes & 46.0 \\
\hline DD & $\begin{array}{l}\text { The loading and unloading of provided equipment is } \\
\text { controlled with a card }\end{array}$ & 99.0 \\
\hline DD1 & Yes & 34.3 \\
\hline DD2 & No & 35.4 \\
\hline DD3 & Sometimes & 30.3 \\
\hline EE & A machinery operating manual exists & 99.0 \\
\hline EE1 & Yes & 22.2 \\
\hline EE2 & No & 13.1 \\
\hline EE3 & Some & 64.7 \\
\hline FF & Machinery operation training is given & 99.0 \\
\hline FF1 & Yes & 39.4 \\
\hline FF2 & No & 13.1 \\
\hline FF3 & Sometimes & 47.5 \\
\hline GG & $\begin{array}{l}\text { Some entity exists that makes the control of on-site risks } \\
\text { obligatory }\end{array}$ & 100.0 \\
\hline GG1 & Yes & 28.0 \\
\hline GG2 & No & 28.0 \\
\hline GG3 & Sometimes & 44.0 \\
\hline
\end{tabular}


Table A4. Cont.

\begin{tabular}{|c|c|c|}
\hline Variable/Category Codes & Variables/Category of Variables & Frequency $(\%)$ \\
\hline $\mathbf{H H}$ & Which entity obliges the control of on-site risks & 61.0 \\
\hline HH1 & Contractor or developer & 59.0 \\
\hline $\mathrm{HH} 2$ & The Social Security Institute and the Ministry of Work & 1.6 \\
\hline HH3 & Contractor or developer and the Ministry of Work & 1.6 \\
\hline $\mathrm{HH} 4$ & $\begin{array}{l}\text { Contractor or developer and the Ministry of Work and the } \\
\text { local authority }\end{array}$ & 6.6 \\
\hline HH5 & The Social Security Institute & 8.2 \\
\hline HH6 & The Ministry of Work and the local authority & 3.3 \\
\hline HH7 & The Ministry of Work & 18.1 \\
\hline $\mathrm{HH} 8$ & Contractor or developer and the Social Security Institute & 1.6 \\
\hline II & Safety networks located on site & 100.0 \\
\hline II1 & Yes & 25.0 \\
\hline II2 & No & 40.0 \\
\hline II3 & Sometimes & 35.0 \\
\hline $\mathrm{JJ}$ & Lighting is considered on site & 99.0 \\
\hline JJ1 & Yes & 37.4 \\
\hline $\mathrm{JJ} 2$ & No & 10.1 \\
\hline $\mathrm{JJ} 3$ & Sometimes & 52.5 \\
\hline KK & Ventilation is considered on site & 99.0 \\
\hline KK1 & Yes & 24.2 \\
\hline KK2 & No & 56.6 \\
\hline KK3 & Sometimes & 19.2 \\
\hline LL & Protection against noise is considered on site & 98.0 \\
\hline LL1 & Yes & 16.3 \\
\hline LL2 & No & 58.2 \\
\hline LL3 & Sometimes & 25.5 \\
\hline
\end{tabular}

Table A5. Nomenclature and frequency of the categories of variables for Prevention Activities and Health and Safety Management in the company and on site (4th part).

\begin{tabular}{ccc}
\hline Variable/Category Codes & Variables/Category of Variables & Frequency (\%) \\
\hline MM & Electric cable protection is installed on site & 96.0 \\
MM1 & Yes & 41.7 \\
MM2 & No & 20.8 \\
MM3 & Sometimes & 37.5 \\
\hline NN & Types of clothing worn by personnel on site & 100.0 \\
NN1 & T-shirt & 2.0 \\
NN2 & Hi-viz jacket & 14.0 \\
NN3 & No specific work clothes & 1.0 \\
NN4 & Others (uniform or canvas trousers) & 4.0 \\
NN5 & T-shirt and Hi-viz jacket & 37.0 \\
NN6 & T-shirt and others (Uniform or canvas trousers) & 12.0 \\
NN7 & T-shirt and Hi-viz jacket and others (uniform or canvas trousers) & 16.0 \\
\hline NN8 & T-shirt, Hi-viz jacket, work smock and others (uniform or & 6.0 \\
\hline NN9 & canvas trousers) & 3.0 \\
NN10 & Hi-viz jacket and others (uniform or canvas trousers) & 2.0 \\
NN11 & Hi-viz jacket and work smock & 2.0 \\
NN12 & T-shirt, Hi-viz jacket and work smock & 1.0 \\
\hline OO & Hi-viz jacket, work smock and others (uniform or canvas trousers) & 100.0 \\
\hline OO1 & An action protocol is available in the case of an on-site accident & 92.0 \\
OO2 & Yes & 8.0 \\
\hline
\end{tabular}


Table A5. Cont.

\begin{tabular}{|c|c|c|}
\hline Variable/Category Codes & Variables/Category of Variables & Frequency $(\%)$ \\
\hline PP & Where an on-site accident victim is treated $^{1}$ & 93.0 \\
\hline PP3 & The nearest Social Security Institute & 6.5 \\
\hline PP7 & $\begin{array}{l}\text { The nearest infirmary, health center, public hospital, Social Security } \\
\text { Institute, or private hospital/clinic }\end{array}$ & 25.8 \\
\hline PP8 & $\begin{array}{l}\text { The nearest infirmary, health center, public hospital, or Social } \\
\text { Security Institute }\end{array}$ & 7.5 \\
\hline PP13 & The nearest infirmary, public hospital, or Social Security Institute & 9.7 \\
\hline PP14 & $\begin{array}{l}\text { The nearest health center, public hospital or Social Security Institute, } \\
\text { or a private hospital/clinic }\end{array}$ & 5.4 \\
\hline QQ & Any entity contacted following accidents suffered on site & 97.0 \\
\hline QQ1 & Yes & 13.4 \\
\hline QQ2 & No & 42.3 \\
\hline QQ3 & Sometimes & 44.3 \\
\hline $\mathbf{R R}$ & Entity or organization contacted after an accident has occurred & 49.0 \\
\hline RR1 & Contractor or developer & 71.4 \\
\hline RR3 & Others & 4.1 \\
\hline RR4 & Contractor or developer and the Ministry of Work & 12.2 \\
\hline RR5 & Contractor, developer, and the Guatemalan Social Security Institute & 6.1 \\
\hline RR6 & The Guatemalan Social Security Institute & 2.1 \\
\hline RR7 & The Ministry of Work & 4.1 \\
\hline EEE & Company awareness of the risk of suffering on-site accidents & 100.0 \\
\hline EEE1 & Low awareness of accident risk & 63.0 \\
\hline EEE2 & Medium awareness of accident risk & 33.0 \\
\hline EEE3 & High awareness of accident risk & 4.0 \\
\hline
\end{tabular}

${ }^{1}$ The other categories were not included as many were not representative.

Table A6. Nomenclature and frequency of the categories of the health and safety variables for Contractor Companies.

\begin{tabular}{|c|c|c|}
\hline Variable/Category Codes & Variables/Category of Variables & Frequency $(\%)$ \\
\hline SS & A Health and Safety Plan is prepared for the jobs carried out & 82.0 \\
\hline SS1 & Yes & 13.4 \\
\hline SS2 & No & 34.2 \\
\hline SS3 & Sometimes & 52.4 \\
\hline TT & What the Health and Safety Plan is based upon ${ }^{1}$ & 57.0 \\
\hline TT1 & A Health and Safety Study & 12.3 \\
\hline TT2 & A risk assessment is only requested from the subcontractor & 3.5 \\
\hline TT3 & Prior meetings with the subcontractor & 38.6 \\
\hline TT4 & Others & 26.3 \\
\hline TT5 & On nothing & 3.5 \\
\hline TT6 & $\begin{array}{l}\text { A Health and Safety Study and prior meetings with the } \\
\text { subcontractor }\end{array}$ & 5.2 \\
\hline TT8 & $\begin{array}{l}\text { A risk assessment is requested from the subcontractor and prior } \\
\text { meetings are held with them }\end{array}$ & 1.8 \\
\hline TT9 & $\begin{array}{l}\text { A Health and Safety Study, a risk assessment requested from the } \\
\text { subcontractor and prior meetings are held with them }\end{array}$ & 7.0 \\
\hline TT10 & $\begin{array}{l}\text { A Health and Safety Study, a risk assessment requested from the } \\
\text { subcontractor and prior meetings are held with them, and others }\end{array}$ & 1.8 \\
\hline
\end{tabular}


Table A6. Cont.

\begin{tabular}{|c|c|c|}
\hline Variable/Category Codes & Variables/Category of Variables & Frequency $(\%)$ \\
\hline UU & $\begin{array}{l}\text { The stipulations of the Health and Safety Plan are complied with } \\
\text { on site }\end{array}$ & 74.0 \\
\hline UU1 & Always & 20.3 \\
\hline UU2 & Partially & 62.1 \\
\hline UU3 & Never & 17.6 \\
\hline VV & $\begin{array}{l}\text { Copies of the Health and Safety Plan are sent to the } \\
\text { subcontractors }\end{array}$ & 74.0 \\
\hline VV1 & Yes & 14.9 \\
\hline VV2 & No & 41.9 \\
\hline VV3 & Sometimes & 43.2 \\
\hline WW & Conoce al Coordinador de Seguridad y Salud de la obra & 76.0 \\
\hline WW1 & Yes & 42.1 \\
\hline WW2 & No & 57.9 \\
\hline$X X$ & The on-site Health and Safety Coordinator is known ${ }^{1}$ & 38.0 \\
\hline XX1 & Not known & 7.9 \\
\hline$X X 2$ & Once a month & 5.3 \\
\hline $\mathrm{XX3}$ & Once a fortnight & 15.8 \\
\hline$X X 4$ & One or two days a week & 21.1 \\
\hline YY & $\begin{array}{l}\text { The developer evaluated the health and safety measures that the } \\
\text { contractor company would undertake when awarding the work. }\end{array}$ & 74.0 \\
\hline YY1 & Yes & 16.2 \\
\hline YY2 & No & 29.7 \\
\hline YY3 & Sometimes & 54.1 \\
\hline AAA & $\begin{array}{l}\text { Safety meetings were held with the subcontractors to disclose } \\
\text { the progress and incidents of on-site safety conditions }\end{array}$ & 79.0 \\
\hline AAA1 & Yes & 15.2 \\
\hline AAA2 & No & 46.8 \\
\hline AAA3 & Sometimes & 38.0 \\
\hline BBB & Who paid the Health and Safety Coordinator's fees & 49.0 \\
\hline BBB1 & Contractor & 44.9 \\
\hline BBB2 & Developer & 32.7 \\
\hline BBB4 & Contractor and developer & 22.4 \\
\hline $\mathrm{CCC}$ & $\begin{array}{l}\text { Do you consider that the creation of a Classification of } \\
\text { Contractor Companies, based on criteria of quality and } \\
\text { management of workplace risk prevention would contribute } \\
\text { favorably to improving safety conditions on the worksite? }\end{array}$ & 81.0 \\
\hline CCC1 & Yes & 51.8 \\
\hline CCC2 & No & 2.5 \\
\hline CCC3 & Probably & 45.7 \\
\hline DDD & $\begin{array}{l}\text { When you subcontract a worksite activity, do you evaluate the } \\
\text { subcontractor based on their levels of safety? }\end{array}$ & 80.0 \\
\hline DDD1 & Yes & 10.0 \\
\hline DDD2 & No & 42.5 \\
\hline DDD3 & Sometimes & 47.5 \\
\hline
\end{tabular}

${ }^{1}$ The other categories were not included as many were not representative.

Table A7. Discrimination measures of the variables in each dimension.

\begin{tabular}{cccc}
\hline \multirow{2}{*}{ Variables } & \multicolumn{2}{c}{ Dimension } & \multirow{2}{*}{ Mean } \\
\cline { 2 - 3 } & $\mathbf{1}$ & $\mathbf{2}$ & \\
\hline $\mathrm{A}$ & 0.143 & 0.155 & 0.149 \\
$\mathrm{~B}$ & 0.382 & 0.264 & 0.323 \\
\hline
\end{tabular}


Table A7. Cont.

\begin{tabular}{|c|c|c|c|}
\hline \multirow{2}{*}{ Variables } & \multicolumn{2}{|c|}{ Dimension } & \multirow{2}{*}{ Mean } \\
\hline & 1 & 2 & \\
\hline C & 0.357 & 0.487 & 0.422 \\
\hline $\mathrm{D}$ & 0.157 & 0.330 & 0.244 \\
\hline $\mathrm{E}$ & 0.182 & 0.639 & 0.411 \\
\hline $\mathrm{F}$ & 0.162 & 0.596 & 0.379 \\
\hline G & 0.167 & 0.144 & 0.156 \\
\hline $\mathrm{H}$ & 0.342 & 0.065 & 0.203 \\
\hline $\mathrm{I}$ & 0.398 & 0.116 & 0.257 \\
\hline $\mathrm{J}$ & 0.398 & 0.337 & 0.368 \\
\hline $\mathrm{K}$ & 0.594 & 0.365 & 0.480 \\
\hline $\mathrm{L}$ & 0.610 & 0.021 & 0.316 \\
\hline M & 0.621 & 0.123 & 0.372 \\
\hline $\mathrm{N}$ & 0.423 & 0.271 & 0.347 \\
\hline $\mathrm{O}$ & 0.399 & 0.308 & 0.354 \\
\hline $\mathrm{P}$ & 0.135 & 0.334 & 0.234 \\
\hline Q & 0.098 & 0.138 & 0.118 \\
\hline $\mathrm{R}$ & 0.333 & 0.099 & 0.216 \\
\hline$S$ & 0.113 & 0.121 & 0.117 \\
\hline $\mathrm{T}$ & 0.365 & 0.332 & 0.349 \\
\hline $\mathrm{U}$ & 0.665 & 0.162 & 0.413 \\
\hline $\mathrm{V}$ & 0.717 & 0.329 & 0.523 \\
\hline W & 0.574 & 0.195 & 0.384 \\
\hline$x$ & 0.658 & 0.183 & 0.420 \\
\hline $\mathrm{Y}$ & 0.620 & 0.434 & 0.527 \\
\hline $\mathrm{Z}$ & 0.673 & 0.382 & 0.528 \\
\hline $\mathrm{ZZ}$ & 0.695 & 0.213 & 0.454 \\
\hline $\mathrm{AA}$ & 0.492 & 0.375 & 0.434 \\
\hline BB & 0.558 & 0.264 & 0.411 \\
\hline $\mathrm{CC}$ & 0.523 & 0.247 & 0.385 \\
\hline DD & 0.276 & 0.198 & 0.237 \\
\hline $\mathrm{EE}$ & 0.480 & 0.157 & 0.318 \\
\hline $\mathrm{FF}$ & 0.196 & 0.214 & 0.205 \\
\hline GG & 0.568 & 0.369 & 0.469 \\
\hline $\mathrm{HH}$ & 0.176 & 0.256 & 0.216 \\
\hline II & 0.721 & 0.114 & 0.418 \\
\hline $\mathrm{JJ}$ & 0.524 & 0.100 & 0.312 \\
\hline KK & 0.728 & 0.143 & 0.436 \\
\hline LL & 0.623 & 0.073 & 0.348 \\
\hline MM & 0.232 & 0.216 & 0.224 \\
\hline $\mathrm{NN}$ & 0.427 & 0.304 & 0.366 \\
\hline $\mathrm{OO}$ & 0.005 & 0.043 & 0.024 \\
\hline $\mathrm{PP}$ & 0.511 & 0.446 & 0.478 \\
\hline QQ & 0.437 & 0.194 & 0.315 \\
\hline $\mathrm{RR}$ & 0.187 & 0.146 & 0.166 \\
\hline EEE & 0.043 & 0.018 & 0.030 \\
\hline SS & 0.409 & 0.334 & 0.372 \\
\hline $\mathrm{TT}$ & 0.130 & 0.579 & 0.355 \\
\hline UU & 0.277 & 0.304 & 0.291 \\
\hline VV & 0.339 & 0.305 & 0.322 \\
\hline WW & 0.516 & 0.358 & 0.437 \\
\hline$X X$ & 0.115 & 0.364 & 0.239 \\
\hline YY & 0.328 & 0.366 & 0.347 \\
\hline AAA & 0.805 & 0.451 & 0.628 \\
\hline BBB & 0.050 & 0.253 & 0.151 \\
\hline CCC & 0.178 & 0.141 & 0.160 \\
\hline DDD & 0.284 & 0.285 & 0.284 \\
\hline Active Total & 22.122 & 14.765 & 18.443 \\
\hline
\end{tabular}




\section{References}

1. Cheng, C.W.; Leu, S.S.; Lin, C.C.; Chihhao, F. Characteristic analysis of occupational accidents at small construction enterprises. Saf. Sci. 2010, 48, 698-707. [CrossRef]

2. Martínez-Aires, M.D.; Rubio Gámez, M.C.; Gibb, A. Prevention through design: The effect of European Directives on construction workplace accidents. Saf. Sci. 2010, 48, 248-258. [CrossRef]

3. Chia-Wen, L.; Tsung-Lung, C. Reducing occupational injuries attributed to in attentional blindness in the construction industry. Saf. Sci. 2016, 89, 129-137. [CrossRef]

4. Raheem, A.A.; Issa, R.R.A. Safety implementation framework for Pakistani construction industry. Saf. Sci. 2016, 82, 301-314. [CrossRef]

5. Reis, C.M.; Machado, T.L.; Mieiro, M.A.A.; Oliveira, C. Safety coordinator specific on a road construction. Occup. Saf. Hyg. 2016, IV, 519-522.

6. Katarzyna, M.; Bartosz, M. Methodology of improving occupational safety in the construction industry on the basis of the TWI program. Saf. Sci. 2017, 92, 225-231. [CrossRef]

7. Yuan, J.; Yi, W.; Miao, M.; Zhang, L. Evaluating the impacts of health, social network and capital on craft efficiency and productivity: A case study of construction workers in China. Int. J. Environ. Res. Public Health 2018, 15, 345. [CrossRef] [PubMed]

8. López-Alonso, M.; Ibarrondo-Dávila, M.P.; Rubio-Gámez, M.C.; Muñoz, T.G. The impact of health and safety investment on construction company costs. Saf. Sci. 2013, 60, 151-159. [CrossRef]

9. Feng, Y.; Teo, E.A.L.; Ling, F.Y.Y.; Low, S.P. Exploring the interactive effects of safety investments, safety culture and project hazard on safety performance: An empirical analysis. Int. J. Proj. Manag. 2014, 32, 932-943. [CrossRef]

10. Feng, Y.; Zhang, S.; Wu, P. Factors influencing workplace accident costs of building projects. Saf. Sci. 2015, 72, 97-104. [CrossRef]

11. Ibarrondo-Dávila, M.P.; López-Alonso, M.; Rubio-Gámez, M.C. Managerial accounting for safety management. The case of a Spanish construction company. Saf. Sci. 2015, 79, 116-125. [CrossRef]

12. Lopez-Valcarcel, A. Occupational safety and health in the construction work. Afr. Newsl. Occup. Health Saf. 2001, 11, 61-63.

13. Tadesse, S.; Israel, D. Occupational injuries among building construction workers in Addis Ababa, Ethiopia. J. Occup. Med. Toxicol. 2016, 11, 16. [CrossRef] [PubMed]

14. Sousa, V.; Almeida, N.M.; Dias, L.A. Risk-based management of occupational safety and health in the construction industry-Part 1: Background knowledge. Saf. Sci. 2014, 66, 75-86. [CrossRef]

15. Hinze, J.; Wiegand, F. Role of designers in construction worker safety. J. Constr. Eng. Manag. 1992, 118, 677-684. [CrossRef]

16. Arévalo, C. Integración de la prevención en el diseño de las obras de construcción: Relación con la siniestralidad laboral, análisis de su regulación normativa, bases conceptuales y desarrollo internacional. Inf. Constr. 2013, 65, 325-334. [CrossRef]

17. Gillen, M.; Kools, S.; Sum, J.; McCall, C.; Moulden, K. Construction workers' perceptions of management safety practices: A qualitative investigation. Work 2004, 23, 245-256. [PubMed]

18. Alli, B.O. Fundamental Principles of Occupational Health and Safety; International Labour Organization (ILO): Geneva, Switzerland, 2001.

19. Kim, S.C.; Ro, Y.S.; Shin, S.D.; Kim, J.Y. Preventive effects of safety kelmets on traumatic brain injury after work-related falls. Int. J. Environ. Res. Public Health 2016, 13, 1063. [CrossRef] [PubMed]

20. Liang, H.; Lin, K.-Y.; Zhang, S.; Su, Y. The impact of coworkers' safety violations on an individual worker: A social contagion effect within the construction crew. Int. J. Environ. Res. Public Health 2018, 15, 773. [CrossRef] [PubMed]

21. Zack, M. The Safety Manager's Guide to Personal Protective Equipment. Occup. Hazards 2013, 126, 19.

22. Ulang, N.M.; Salim, N.S.; Baharum, F.; Agus Salim, N.A. Construction Site Workers' Awareness on Using Safety Equipment: Case Study. In Proceedings of the Building Surveying, Facilities Management and Engineering Conference (BSFMEC 2014), MATEC Web of Conferences Volume 15, Perak, Malaysia, 27 August 2014; Othuman Mydin, M.A., Ed.; EDP Sciences: Les Ulis, France, 2014. Art 01023.

23. Vinodkumar, M.N.; Bhasi, M. Safety management practices and safety behaviour: Assessing the mediating role of safety knowledge and motivation. Accid. Anal. Prev. 2010, 42, 2082-2093. [CrossRef] [PubMed] 
24. Bridi, M.E.; Pellicer, E.; Fabro, F.; Viguer, M.E.; Echeveste, M.E.S.; Formoso, C.T. IdentificaÇão de práticas de gestão da SST em obras de construÇão civil. Ambiente Construído 2013, 13, 43-58. [CrossRef]

25. Alarcón, L.F.; Acuña, D.; Diethelm, S.; Pellicer, E. Strategies for improving safety performance in construction firms. Accid. Anal. Prev. 2016, 94, 107-118. [CrossRef] [PubMed]

26. Tam, C.M.; Zeng, S.X.; Deng, Z.M. Identifying elements of poor construction safety in China. Saf. Sci. 2004, 42, 569-586. [CrossRef]

27. Goh, K.C.; Goh, H.H.; Goh, H.H.; Omar, M.F.; Toh, T.C.; Zin, A.A.M. Accidents Preventive Practice for High-Rise Construction. In Proceedings of the 3rd International Conference on Civil and Environmental Engineering for Sustainability (IConCEES 2015), MATEC Web of Conferences Volume 47, Melaka, Malaysia, 1-2 December 2015; Rahman, N.A., Jaini, Z.M., Yunus, R., Rahmat, S.N., Eds.; EDP Sciences: Les Ulis, France, 2016. Art 04004. [CrossRef]

28. Haslam, R.A.; Hide, S.A.; Gibb, A.G.F. Contributing factors in construction accidents. Appl. Ergon. 2005, 36, 401-415. [CrossRef] [PubMed]

29. Carrillo-Castrillo, J.A.; Trillo-Cabello, A.F.; Rubio-Romero, J.C. Construction accidents: Identification of the main associations between causes, mechanisms and stages of the construction process. Int. J. Occup. Saf. Ergon. 2017, 23, 240-250. [CrossRef] [PubMed]

30. Zeng, S.X.; Tam, V.W.Y.; Tam, C.M. Towards occupational health and safety systems in the construction industry of China. Saf. Sci. 2008, 46, 1155-1168. [CrossRef]

31. ILO. Safety and Health in Building and Civil Engineering Work; International Labor Office (ILO): Geneva, Switzerland, 1985.

32. Weinstein, W.; Gambatese, J.; Hecker, S. Can design improve construction safety? Assessing the impact of a collaborative safety-in-design process. J. Constr. Eng. Manag. ASCE 2005, 131, 1125-1134. [CrossRef]

33. López-Arquillos, A.; Rubio-Romero, J.C.; Martínez-Aires, M.D. Prevention through Design (PtD). The importance of the concept in Engineering and Architecture university courses. Saf. Sci. 2015, 73, 8-14. [CrossRef]

34. Gambatese, J.; Behm, M.; Rajendran, S. Design's role in construction accident causality and prevention: Perspectives from an expert panel. Saf. Sci. 2008, 46, 675-691. [CrossRef]

35. Toole, T.M.; Gambatese, J. The trajectories of construction prevention through design. J. Saf. Res. 2008, 39, 225-230. [CrossRef] [PubMed]

36. Saunders, L.W.; Kleiner, B.M.; McCoy, A.P.; Ellis, K.P.; Smith-Jackson, T.; Wernz, C. Developing an inter-organizational safety climate instrument for the construction industry. Saf. Sci. 2017, 98, 17-24. [CrossRef]

37. Teo, A.L.E.; Ofori, G.; Tjandra, I.K.; Kim, H. Design for safety: Theoretical framework of the safety aspect of BIM system to determine the safety index. Constr. Econ. Build. 2016, 16, 1-18. [CrossRef]

38. Alomari, K.; Gambatese, J.; Anderson, J. Opportunities for using Building Information Modeling to improve worker safety performance. Safety 2017, 3, 7. [CrossRef]

39. Martínez-Aires, M.D.; López-Alonso, M.; Martínez-Rojas, M. Building information modeling and safety management: A systematic review. Saf. Sci. 2018, 101, 11-18. [CrossRef]

40. ILO-OSH 2001. The Guidelines on Occupational Safety and Health Management System. ILO-OSH 2001; International Labor Office (ILO): Geneva, Switzerland, 2001.

41. BS-OHSAS 18001. Occupational Health and Safety Management (OHS); British Standars Institution (BSI): London, UK, 1999.

42. ISO 45001. Occupational Health and Safety Management Systems-Requirements with Guidance for Use; International Organization for Standardization (ISO): Geneva, Switzerland, 2018.

43. MINTRAB (Ministerio de Trabajo y Asistencia Social de Guatemala). Reglamento General sobre Higiene y Seguridad en el trabajo. Available online: http://www.mintrabajo.gob.gt/images/organizacion/ leyesconveniosyacuerdos/Leyes_Ordinarias/ACUERDO_GUBERNATIVO_229-2014.pdf (accessed on 5 June 2018).

44. Consejo Nacional de Salud y Seguridad Ocupacional: Guatemala. Perfil Diagnóstico Nacional sobre Condiciones de Trabajo, Salud y Seguridad Ocupacional. Available online: https://www.ilo.org/wcmsp5/ groups/public/@ed_protect/@protrav/@safework/documents/policy/wcms_187681.pdf (accessed on 8 October 2018).

45. BE (Boletín Estadístico). Prestaciones en salud año 2016. In Boletín Estadístico 2016; Departamento Actuarial y Estadístico del Instituto Guatemalteco de Seguridad Social: Guatemala, 2016. 
46. Dong, X. Long work hours, work scheduling and work-related injuries among construction workers in the United States. Scand. J. Work Environ. Health 2005, 31, 329-335. [CrossRef] [PubMed]

47. Calderón-Gálvez, C.G. Análisis de modelos de gestión de seguridad y salud en las PYMES del sector de la construcción. Ph.D. Thesis, University of Granada, Granada, Spain, 2006.

48. Pérez-Alonso, J.; Carreño-Ortega, A.; Callejón-Ferre, A.J.; Vázquez-Cabrera, F.J. Preventive activity in the greenhouse-construction industry of south-eastern Spain. Saf. Sci. 2011, 49, 345-354. [CrossRef]

49. INE. Clasificación de empresas constructoras por tamaño en base al Acuerdo Gubernativo 211-2015 del Ministerio de Economía. In Directorio Nacional Estadístico de Empresas; Instituto Nacional de Estadística: Guatemala.

50. Chen, L.; Mohamed, S. The strategic importance of tacit knowledge management activities in construction. Constr. Innov. 2009, 10, 138-163. [CrossRef]

51. Chia-Fen, C.; Tin-Chang, C.; Hsin-I, T. Accident patterns and prevention measures for fatal occupational falls in the construction industry. Appl. Ergon. 2005, 36, 391-400. [CrossRef] [PubMed]

52. Fabiano, B.; Curro, F.; Pastorino, R. A study of the relationship between occupational injuries and firm size and type in the Italian industry. Saf. Sci. 2004, 42, 587-600. [CrossRef]

53. Sorensen, O.H.; Hasle, P.; Bach, E. Working in small enterprises-Is there a special risk? Saf. Sci. 2007, 45, 1044-1059. [CrossRef]

54. Hasle, P.; Kines, P.; Andersen, L. Small enterprise owner's accident causation attribution and prevention. Saf. Sci. 2008, 47, 9-19. [CrossRef]

55. Beaver, G. Management and the small firm. Strateg. Chang. 2003, 12, 63-68. [CrossRef]

56. Pérez-Alonso, J.; Carreño-Ortega, A.; Vázquez-Cabrera, F.J.; Callejón-Ferre, A.J. Accidents in the greenhouse-construction industry of SE Spain. Appl. Ergon. 2012, 43, 69-80. [CrossRef] [PubMed]

57. Aboagye-Nimo, E.; Raiden, A.; King, A.; Tietze, S. Using tacit knowledge in training and accident prevention. Manag. Procure. Law 2015, 168, 232-240. [CrossRef]

58. Berry, A.J.; Coad, A.F.; Harris, E.P.; Otley, D.T.; Stringer, C. Emerging themes in management control: A review of recent literature. Br. Account. Rev. 2009, 41, 2-20. [CrossRef]

59. Akroush, N.S.; El-adaway, I.H. Utilizing Construction Leading Safety Indicators: Case Study of Tennessee. J. Manag. Eng. 2017, 33. [CrossRef]

60. Rodríguez-Garzón, I.; Lucas-Ruiz, V.; Martínez-Fiestas, M.; Delgado-Padial, A. Association between perceived risk and training in the construction industry. J. Constr. Eng. Manag. 2014, 141, 04014095. [CrossRef]

61. Rodríguez-Garzón, I.; Martínez-Fiestas, M.; Delgado-Padial, A.; Lucas-Ruiz, V. An Exploratory Analysis of Perceived Risk among Construction Workers in Three Spanish-Speaking Countries. J. Constr. Eng. Manag. 2016, 142, 045016066. [CrossRef]

(C) 2018 by the authors. Licensee MDPI, Basel, Switzerland. This article is an open access article distributed under the terms and conditions of the Creative Commons Attribution (CC BY) license (http:/ / creativecommons.org/licenses/by/4.0/). 